\title{
URSI National Committee Report, XIV General Assembly, Tokyo, September 1963: Commission 7. Radio Electronics
}

\author{
Review of developments occurring within the United States in the field of Radio \\ Electronics during the triennium 1960 through 1962. \\ 1. Progress in microwave power tubes. J. Feinstein \\ 2. 1960-1963 advances in the state-of-the-art of low-noise beam-type microwave tubes. \\ R. W. Peter \\ 3. Developments in semiconductor devices in the U.S.A. for the period 1960-1963. \\ A. van der Ziel \\ 4. Parametric devices. R. Rafuse \\ 5. Millimeter-wave techniques. A. Karp and J. Allison \\ 6. Status of gas lasers. W. R. Bennett, Jr. \\ 7. Noise in masers. Hermann A. Haus \\ 8. Nonlinear optical properties of solids. P. S. Pershan \\ 9. Highlights of progress on satellite devices. C. C. Cutler and J. R. Pierce \\ 10. Waves in plasmas. A. Bers and P. Chorney
}

\section{Progress in Microwave Power Tubes}

\section{J. Feinstein*}

The microwave tube field reached maturity during the past three years. This is reflected in the nature of the advances made which consist chiefly of the attainment of higher power and greater gain and bandwidth in both linear beam and crossed-field types.

While the exploration of new principles led to deeper insight into electron-wave interaction, the performance competition from well-established tube types has thus far prevented the emergence of practical new types.

\section{Klystrons}

The attainment of $100 \mathrm{kw}$ of $\mathrm{CW}$ power at 8 $\mathrm{Gc} / \mathrm{s}$ [McCune et al., 1961] is probably the most spectacular current feat in the tube field. This performance is a result of excellent beam control, good thermal engineering, and new output window fabrication techniques. Similarly, impressive amounts of power have been obtained at other frequency bands in single tubes employing solid beams [Holaday and Petersen, 1961]. Stageger tuning and coupled cavity output circuits [Biss, 1962] have led to electronic bandwidths of 5 percent for $1 \mathrm{Mw}$ peak power klystrons. The principle of distributed klystron interaction employing slow wave structures in lieu of gaps has been verified experimentally [Chodorow and Wesselberg, 1961]. Large signal calculations which take into account the effect of

*S.F.D. Laboratories, Inc. N.J. space charge and of velocity spread have been made [Weber, 1960] and form the basis for optimizing parameters such as drift tube length.

As the limit of power attainable in a single tube is approached, methods of paralleling tubes are receiving increased attention. The multiple beam klystron [Boyd et al., 1962] represents one such method in which corresponding cavities of adjacent klystrons are coupled to form a traveling wave structure.

\section{Traveling Wave Tubes}

A measure of the engineering progress which has been made in this area during the review period may be gleaned from the fact that $1 / 2 \mathrm{w} C W$ at 5 to $6 \mathrm{~mm}$ [McDowell et al., 1960] represented the frontier of the millimeter wave amplifier field at the start of the period while $150 \mathrm{w} \mathrm{CW}$ in the same band [Nevins, 1962] is the current frontier. The first tube employed a helix while the second operates on the first forward space harmonic of a (inductively) coupled cavity structure.

For satellite repeater applications $10 \mathrm{w}$ amplifier tubes of about 30 percent efficiency and weighing under $1 \mathrm{lb}$ have been developed [Bodmer, 1961; Highstretc et al., 1962].

Considerable effort has been devoted to multiple depressed collectors [Dunn et al., 1960] but only a single stage of depression has appeared in practical tubes.

A backward wave oscillator employing a coupled cavity circuit has generated $2 \mathrm{~W} \mathrm{CW}$ over the frequency range 50 to $75 \mathrm{Gc} / \mathrm{s}$ [Schumacher, 1962]. 


\section{Crossed-Field Tubes}

Magnetron oscillators based on the circular electric mode coupling principle have attained peak power levels of $1.5 \mathrm{Mw}$ at X-band [Cook et al., 1961] and $300 \mathrm{kw}$ at $8.6 \mathrm{~mm}$ [La Plante, 1963]. The latter tube is of inverted type leading to a large increase in cathode surface area and extracting the power in a circular electric mode output waveguide. A $K_{u}$ band carcinatron has been developed with an output power of $100 \mathrm{w}$ [Moats et al., 1962]. A depressed collector has been employed to improve the efficiency of this tube type [Oscpchuk, 1962]. Megawatt peak power, re-entrant stream traveling wave amplifiers have attained saturated gains of 20 to $30 \mathrm{db}$ over 10 percent bandwidths [McDowell et al., 1962]. A drift space is employed in these tubes to debunch the re-entering stream, while a control electrode located in this space functions as a modulating anode.

A $25 \mathrm{w}$ CW 1-lb, S-band amplitron has been designed for space application. This tube has 20 db gain and 50 percent efficiency [Teich et al., 1962]. Development of forward-wave, injected beam, CW amplifiers has reached the $1 \mathrm{kw}$ power level. The large signal theory of this type of interaction has been verified experimentally [Anderson, 1961].

\section{Fast Wave Interactions}

Theoretical work on d-c pumped cyclotron wave tubes employing for the most part the coupled mode formulation and the kinetic power viewpoint was carried on extensively during this period [Siegmann, 1960; Gordon, 1960]. Experimentally, the fast wave $(\beta=0)$ couplers introduced by Adler in his RF-pumped, low-noise tubes were combined with periodic structures producing d-c electric or magnetic fields to provide gain [Gordon, 1960; Wesselberg et al., 1962]. By the end of this period most of this work had foundered on the problem of beam control in the presence of a gain mechanism which amplified dc perturbations on the beam.

A cyclotron wave backward wave oscillator which has the novel feature of requiring a first-order RF magnetic field force for its operation was demonstrated [Chow et al., 1962].

A fast wave transverse interaction utilizing periodic magnetic deflection was demonstrated. By operating in a circular electric mode waveguide more than $1 \mathrm{Mw}$ of peak power was obtained above X-band [Phillips, 1960].

\section{Electron Guns}

Supporting work in this category formed the basis for many of the advances recorded above. For solid beams the emphasis was on high perveance (up to five) and high area convergence (up to 1000:1) [Frost et al., 1962]. For more advanced tubes hollow beams were under intensive investigation. These were mainly of the magnetron injection type, and utilized space charge solutions in crossed fields to determine electrode shapes [Kino et al., 1962]. A mathematical approach [Harker, 1960] which made possible convergent computer solutions proved valuable in this area. Methods of focusing hollow beams through long circuits were also explored [Cook, 1961].

Crossed-field gun design methods were also evolved, but $\mathrm{RF}$ instabilities in the resultant beam set limits to the range of parameters which could be successfully employed [Midford et al., 1962].

\section{References}

Anderson, J. R. (1961), Experimental investigation of largesignal traveling wave magnetron theory, IRE Trans. ED-8, No. 3.

Biss, R. (1962), Pulsed megawatt X-band klystron, PGED Meeting (Washington, D.C.).

Bodmer, M. G. (1961), A 4 kMc satellite TWT for the A.T. and T. Communication satellite, PGED Meeting (Washington, D.C.).

Boyd, Dehn, Hickey, Mihran (1962), The multiple beam klystron, IRE Trans. ED-9, No. 3.

Chodorow and Wesselberg (1961), High efficiency klystrons with distributed interaction, IRE Trans. ED-9, No. 1.

Chow and Pantell (1962), The cyclotron resonance backward wave oscillator, Proc. IRE, 48, 1865 (1960); IRE Trans. ED-9, No. 4.

Cook, Drexler, and Feulner (1961), A 1.5 megawatt, high efficiency X-band CEMR coaxial magnetron, PGED Meeting (Washington, D.C.).

Cook, E. J. (1961), Tangential magnetic field immersion of a hollow beam electron gun, IRE Trans. ED-8, No. 2.

Dunn, Borghi, and Wada (1960), A crossed-field multi-segment depressed collector for beam-type tubes, IRE Trans. ED-7, No. 4.

Frost, Purl, and Johnson (1962), Electron guns for solid beams of high perveance and high convergence, Proc. IRE, 50, 1800 .

Gordon, E. I. (1960), A transverse field traveling wave tube, Proc. IRE 48, 1158 .

Gordon, E. I. (1960), Transverse electron beam waves in varying magnetic fields, Bell System Tech. 39, No. 6.

Harker, K. J. (1960), Determination of electrode shapes for axially symmetric Electron Guns, J. Appl. Phys. 31, 2165.

Highstretc and Grabowski (1962), Lightweight TWT for space vehicles, PGED Meeting, Washington, D.C., 1962.

Holaday and Petersen (1961), A $5 \mathrm{Mw}-300 \mathrm{kw}$ klystron at L-band, PGED Meeting (Washington, D.C.).

Kino and Taylor (1962), Design and performance of magnetron injection guns, IRE Trans. ED-9, No. 1.

LaPlante, R. A. (Jan. 1963), Coaxial magnetrons-A new class of tubes, Electronic Industries.

McCune, Maltzer, and Zitelli (1961), A $20 \mathrm{kw}$ C.W. X-band amplifier, Microwave Journal 4, No. 8 (see also Vol. 6, p. 1).

MeDowell, Danielson, and Reed (1960), Half-watt c.w. TWT for 5-6 mm band, Proc. IRE 48, No. 3, 1960.

McDowell and Wilczek (1962), An L-band crossed-field amplifier chain, PGED Meeting (Washington, D.C.).

Midford and Kino (1962), Experiments with a new type adiabatic crossed-field gun, IRE Trans. ED-9, No. 6.

Moats and Fisher (1962), Crossed-field backward-wave oscillators above X-band, PGED Meeting (Washington, D.C.).

Nevins, J. E. (1962), Millimeter wave tubes using the coupled cavity circuit, PGED Meeting (Washington, D.C.).

Oscpchuk, J. M. (1962), The beam miser, a depressed collector for crossed-field traveling wave tubes, Microwave Journal, 5. No. 7 .

Phillips, R. M. (1960), The Ubitron, a high power TWT based on a periodic beam interaction in unloaded waveguide, IRE Trans. ED-\%, No. 4.

Schumacher, R. T. (1962), A 50-75 Ge power backward-wave oscillator, PGED Meeting (Washington, D.C.).

Siegmann, A. E. (1960), Waves on a filamentary electron beam in a transverse field circuit, J. Appl. Phys. vol. 31, 17.

Teich and Brown (1962), Design of CW amplitrons for spaceborne telemetry applications, PGED Meeting (Washington, D.C.)

Webber, S. E. (1960), Large signal energy exchange mechanisms in linear beam tubes, IRE Trans. ED-y, No. 3.

Wesselberg and Blotekjaer (1962), A D.C. Pumped amplifier using space periodic magnetic fields, Proc. IRE 50, 2513 


\title{
2. 1960-1963 Advances in the State-of-the-Art of Low- Noise Beam-Type Microwave Tubes
}

\author{
R. W. Peter*
}

\section{Noise Reduction in Beam-Type Amplifiers- General Aspects}

The traveling-wave tube and the electron-beam parametric amplifier have emerged as the important low-noise beam-type amplifiers. During the last three years no work has been reported on low-noise klystrons and triodes and little work is being done on M-type low-noise amplifiers [Anderson, May 1960]. The best noise factors achieved with these latter tube types are higher by a wide margin than those of the traveling-wave tube and the beam-type parametric amplifier, both of which have reached best noise factors of around $1.5 \mathrm{db}$ in the lower microwave frequency ranges. The basic mechanisms of all beam-type tubes, although different in detail, have certain aspects in common. As coupled wave phenomena, they can be treated in a generalized form [Pease, June 1961]. Beam refrigeration using large magnetic fields, experimentally demonstrated in the beam-type parametric amplifier, may well be applicable to the traveling-wave tube also [Adler and Wade, July 1960]. Cooling of the slow spacecharge wave in the traveling-wave tube using wellproven methods of parametric amplifiers has been proposed but not yet experimentally verified [Forster, November 1962].

\section{Low-Noise Traveling-Wave Tube Amplifiers}

The low-noise traveling-wave tube may be said to have reached the state of a mature product during the past three years. Its noise factor through frequencies up to K-band has been gradually decreasing. This has been achieved by further refining the hollowbeam low-noise gun described earlier [Currie and Forster, April 1958], and by further refining [Bosch and Niclas, March 1962] the solid-beam low-noise gun previously reported [Peter, December 1958]. Both types have been proven to be basically identical, leading to hollow-beam emission under the favorable condition of a strongly divergent electric field at the cathode. The lowest noise factor recently measured with a traveling-wave tube is $1.5 \mathrm{db}$ measured in UHF-band [Vehn and Peter. 19631.

The effect of distributed loss of the helix on the noise factor in traveling-wave tubes [Yariv and Kompfner, May 1961] has been further investigated, [Bloom, June 1961; Israelsen, March 1962]. A noise factor reduction of about $1 \mathrm{db}$ has been dem-

\footnotetext{
*Watkins-Johnson Co., 3333 Hillview Ave., Palo Alto, Calif.
}

onstrated in L-band by cooling the helix to liquid nitrogen temperature [Israelsen and Peter, July 1962].

Production refinement of low-noise traveling-wave tubes for specific applications has led to significant advances which include extreme phase and gain linearity of the amplifier, operational life of more than $10,000 \mathrm{hr}$, permanent-magnet focusing in magnetically shielded packages without loss of noise factor, extremely high tube-to-tube reproducibility, and high limiting capability for large input signals [Mita, 'Takeya, Hayasi, Kakizaki, Yoshida, October 1962].

\section{Noise in Multivelocity Electron Beams}

This is the area where the most radical noise factor improvements are still possible. Extensive study of noise-wave propagation through the potential minimum of a space-charge-limited diode or virtual cathode has been carried out both theoretically and experimentally [Whinnery, October 1960; Vivian, June 1960; Berghammer, September 1960; Mueller, March 1961; Yadavalli, June 1961; Pollack, May 1962; Eichenbaum and Hammer, September 1962]. Experimental results indicate that whenever a potential minimum exists, noise reduction takes place. Theory indicates that the electron-plasma frequency in the potential minimum should be in the order of the signal frequency or higher for effective noise reduction.

Several more or less idealized models of a multivelocity electron beam drifting at low voltage have been investigated. All theories indicate that the two uncorrelated noise waves become partially correlated in a low-velocity drift space [Morrison, November 1960; Gray, February 1960; Berghammer and Bloom, March 1960; Mihran, April 1962; Bobroff, June 1962].

Measurements of the basic noise quantities $S$ and II were made to verify these theories [Zacharias and Smullin, July 1960]. Measurements on a hollow-beam low-noise gun indicated $\mathrm{S}$ to be reduced while $P / S$ remained constant.

Partition noise in electron beams resulting from partial current interception has been investigated [Ashkin and White, August 1960; Hart, August 1962] for axial and transverse beam waves.

In actual tubes partition noise can be essentially eliminated. Further, transverse-to-axial noise wave transformation on a beam passing through electric or magnetic lenses can be minimized by suitable design of the gun and by avoiding periodic magnetic beam focusing. 


\section{Emitters for Low-Noise Electron Guns}

All other factors being the same, a cathode emitting lower-temperature electrons will produce a lower noise factor in the beam-type amplifier. For this reason many studies have been carried out on standard as well as novel cathodes for low-noise electron guns.

The fluctuations in the emission of tungsten-base impregnated barium cathodes were investigated [Brodie, October 1961; Hill and Rouze, April 1962]. Considerable progress and success has been achieved in electron cooling by interaction with a cold plasma. $\beta$-Eucryptite is a preferred source for the cool plasma in front of the cathode [Johnson, September 1962; Eichenbaum, June 1962; Anderson and Harris, 1960]. Electron temperature reduction from 1100 to $300{ }^{\circ} \mathrm{C}$ has been observed.

A new type of cold cathode based upon the tunnel mechanism is being studied. Electrons can tunnel from a core metal into vacuum if a suitable potential configuration exists near the surface inside the emitter. 'This is achieved by applying a small voltage between surface films [Geppert and Barnes, November 1961; Wade, Briggs, and Lesensky, March 1962].

Currents of several hundred microamps have been drawn from tunnel cathodes. The ratio between required cathode power and emitted current is, however, still much higher than that in a thermionic cathode.

\section{Electron-Beam Parametric Amplifier}

Most of the work on the electron beam parametric amplifier was concentrated on the degenerate type where the pump frequency is near twice the signal frequency. In this case, the idler frequency is very near the signal frequency and the noise factor measured with a broadband noise source is the so-called double channel noise figure. Best success has been achieved in the UHF, P- and L-frequency bands at an instantaneous bandwith of up to $100 \mathrm{Mc} / \mathrm{s}$; broadband noise figures of about $1 \mathrm{db}$ and gain from 20 to $45 \mathrm{db}$ have been measured. Degenerate amplifiers have also been made for $\mathrm{S}$ - and C-band. $\mathrm{X}$-band appears to be a practical upper limit due to the linear increase of magnetic field with frequency, 3500 gauss at X-band.

The presence of the idler near the signal frequency is a disadvantage in the/degenerate amplifier. Recent work has resulted in the successful operation of nondegenerate amplifiers in the region of $400 \mathrm{Mc} / \mathrm{s}$ using a $2100 \mathrm{Mc} / \mathrm{s}$ pump. A single-channel noise factor of less than $2 \mathrm{db}$ was obtained. Development of similar nondegenerate tubes for L-band, pumped at $\mathrm{C}$-band, is now in process. For frequencies higher than that it is not yet known how the degenerate amplifier will perform.

Power output, and therefore dynamic range, limitations may be imposed on the electron-beam parametric amplifier by the fact that this tube operates best if the beam potential is below the ionization potential of the residual gas molecules left in the tube.

Considerable progress has been made in advancing the theory of the electron-beam parametric or Adlertype amplifier. [Cook, Louisdell and Quate, January 1960; Lea-Wilson, Adler, Hrbek, and Wade, February 1960; Johnson, February 1960; Heffner and Wade, December 1960; Bridges and Ashkin, March 1960; Gordon, November 1960; Gould and Johnson, February 1961; Adler and Wade, April 1961; Fredericks, May 1961; Gordon, July 1961; Ashkin, June 1961; Chang, March 1961; Bløtekja er, August 1962; Wessel-Berg and Bløtekjaer, September 1962; Adler and Hrbek, January, 1963.]

\section{M-Type Low-Noise Amplifiers}

M-type amplifiers have long been known as noisy amplifiers. Various instabilities of the electron plasma between cathode or sole and anode lead to considerable amounts of noise. These noise producing mechanisms, however, do not necessarily have to be present in the M-type. Considerable improvements in this type of amplifier can, therefore, be expected since present noise performance leaves much to be desired. Results achieved by Kluver on a Kompfnerdip coupler for M-type tubes look particularly promising [Anderson, May 1960; Van Duzer, Whinnery, June 1960; Kluver, June 1960].

\section{Standards and State-of-the-Art Summaries}

A description of the performance of amplifiers and receiving systems has been published as part of the IRE standards on electron tubes [March 1963]. Summaries of the state-of-the-art and the future of low-noise traveling-wave tubes and other low-noise amplifiers for microwaves are available [Currie, June 1960; Wade, May 1961; Israelsen, Peter, September 1962].

\section{References}

Adler, R., and G. Wade (Apr. 1961), Behavior of thermal noise and beam noise in a quadrupole amplifier, Proc. IRE 49, p. 802 .

Adler, R., and G. Wade (July 1960), Beam refrigeration by means of large magnetic fields, JAP 31, p. 1201.

Adler, R., and G. W. Hrbek (Jan. 1963), Non-degenerate electron beam parametric amplifiers, IEEE Trans. Ant. Prop. ED-10, 1.

Anderson, J. R. (May 1960), Noise measurements on an M-type backward-wave amplifier, Proc. IRE, 48, p. 946.

Anderson, J. M., and L. A. Harris (Aug. 1960), Negative glow plasma as a cathode for electron tubes, J. Appl. Phys. 31, p. 1463.

Ashkin, A. (June 1961), A low-noise MW quadrupole amplifier, Proc. IRE 49, p. 1016.

Ashkin, A., and L. D. White (Aug. 1960), Partition noise in electron beams at microwave frequencies, JAP 31, p. 1351.

Beam, W. R. (June 1960), Non-degenerate electron beam parametric devices using transverse interaction: Principles and some experimental results, p. 362, Proc. of the International Congress on Microwave Tubes, Munich.

Berghammer, J. (Sept. 1960), Space-charge effects in ultralow-noise electron guns, RCA Review, 21 , p. 369.

Berghammer, J., and S. Bloom (Mar. 1960), On the nonconservation of noise parameters in multivelocity beams, JAP 31, p. 454.

Blotekjaer, K. (Aug. 1962), Transverse electron beam noise described by filamentary beam parameters, JAP 33 , p. 2409.

Blotekjaer, K., and T. Wessel-Berg (June 1960), Some aspects of cyclotron-wave amplification in time-periodic and spaceperiodic fields, p. 372, Proc. of the International Congress on Microwave Tubes, Munich.

Bloom, S. (June 1961), Effect of distributed-loss noise gen- 
erators on traveling-wave tube noise factor, RCA Review 22, p. 347.

Bobroff, D. L. (June 1962), Reduction of beam noisiness in a drifting multivelocity beam, JAP 33, p. 2142 (L).

Bosch, B. G., and K. B. Niclas (Mar. 1962), Ultra-low-noise traveling-wave tube with simple electron gun structure, Proc. IRE 50, p. 324L.

Bridges, T. J., and A. Ashkin (Mar. 1960), A microwave adler tube, Proc. IRE 48, p. 361.

Bridges, T. J., C. P. Lea-Wilson, and J. C. Vokes (June 1960), Principles of scaling of cyclotron wave amplifiers, p. 352, Proc. of The International Congress on Microwave Tubes, Munich.

Brodie, I. (Oct. 1961), Emission fluctuations of tungsten-based barium dispenser cathodes, JAP 32, p. 2039.

Carroll, J. E. (June 1960), A parametric beam amplifier using Cuccia couplers, p. 356, Proc. of The International Congress on Microwave Tubes, Munich.

Chang, N. C. (Mar. 1961), Noise and bandwidth considerations of Kompfner dip couplers for electron beam parametric amplifiers, Proc. IRE 49, p. 637L.

Cook, J. S., W. H. Louisell, C. F. Quate (Jan. 1960), Spacecharge wave parametric amplifiers, J. Electronics Control 8, p. 1.

Currie, M. R., and D. C. Forster (Apr. 1958), Conditions for minimum noise generation in backward-wave amplifiers, IRE Trans. ED-5, p. 88.

Currie, M. R. (June 1960), Noise phenomena in microwave tubes, p. 392, Proc. of The International Congress on Microwave Tubes, Munich.

Eichenbaum, A. L. (June 1962), The space-charge-neutralized hollow cathode, RCA Review 23, p. 230.

Eichenbaum, A. L., and J. M. Hammer (Sept. 1962), Limiting-current effects in low-noise traveling-wave tube guns, RCA Rev. 23, p. 420.

Everhart, T. E. (June 1960), Space-charge effects in a quadrupole pump, p. 350, Proc. of The International Congress on Microwave Tubes, Munich.

Forster, D. C. (Nov. 1962), Cooling of the slow-space charge wave with application to the traveling-wave tube, IRE Trans. ED-9, p. 449.

Fredericks, R. W. (May 1961), Traveling-wave tube analysis of the adler tube, IRE Trans. ED-8, p. 212.

Geppert, D. V., and C. W. Barnes, Jr. (Nov. 1961), The equivalent noise temperature of the tunnel cathode, IRE, Trans. ED-8, p. 561.

Gordon, E. I. (June 1960), A transverse field traveling-wave tube, Proc. of the International Congress on Microwave Tubes, p. 389, Munich.

Gordon, E. I. (Nov. 1960), Transverse electron beam waves in varying magnetic fields, Bell System Tech. J. 39, p. 1603.

Gordon, E. I. (July 1961), Noise in beam-type parametric amplifiers, Proc. IRE, 49, p. 1208L.

Gould, R. W., and C. C. Johnson, (Feb. 1961), Coupled mode theory of electron-beam parametric amplification, JAP 32, p. 248.

Gray, G. A. (Feb. 1960), Single-velocity equivalents for multivelocity electron streams, JAP 31, p. 370.

Hart, P. A. H. (Aug. 1962), Partition effects in transverse electron beam waves, JAP 33, p. 2401.

Hart, P. A. H., and C. Weber, (June 1960), A transmissionline coupler for a fast wave transverse velocity electron beam amplifier, Proc. of the International Congress on Microwave Tubes, p. 358, Munich.

Heffner, H., and G. Wade (Dec. 1960), Noise figure and gain of parametric converters, JAP 31, p. 2316L

Hill, R. F., and S. Rouze, (Apr. 1962), Emission characteristics of a philips impregnated cathode, JAP, 33, p. $1607 \mathrm{~L}$.

IRE standards on electron tubes, description of the performance of amplifiers and receiving systems, Proc. IRE, 51, p. 434 (March 1963).

Israelsen, B. P. (Mar. 1962), The effect of helix loss on noise figure on traveling-wave tubes, IRE Trans. ED-9, p. 217.

Israelsen, B. P., and R. W. Peter, (July 1962), Traveling-wave tube with $1.7 \mathrm{db}$ noise figure in L-band, Proc. IRE, 50, p. $1683 \mathrm{~L}$

Israelsen, B. P., and R. W. Peter (Sept. 1962), Progress in low-noise traveling-wave tube development, presented at the International Microwave Congress in The Hague.
Johnson, C. C. (Feb. 1960), Theory of fast-wave parametric amplification, JAP 31, p. 338.

Johnson, F. M. (Sept. 1962), Studies of the ion emitter betaeucryptite, RCA Rev. 23, p. 427.

Kluver, J. W. (June 1960), An M-type fast cyclotron wave coupler, p. 367, Proc. of The International Congress on Microwave Tubes, Munich.

Kompfner, R. (June 1960), Ursachen des Rauschens in Zyklotronwellen-Verstarken, p. 403, Proc. of The International Congress on Microwave Tubes, Munich.

Lea-Wilson, C. P., R. Alder, G. Hrbek, and G. Wade (Feb. 1960), Some possible causes of noise in Adler tubes, Proc. IRE 48, p. 255.

Mihran, T. G. (Apr. 1962), RF current behavior in electron beam with de velocity spread, JAP 33, p. 1582

Mita, S., T. Takeya, S. Hayasi, K. Kakizaki, and T. Yoshida (Oct. 1962), Large signal behavior of a low-noise travelingwave tube and its application to pulse radar, Proc. IRE 50, p. 2143.

Morrison, J. A. (Nov. 1960), Noise propagation in drifting multi-velocity electron beams, JAP 31, p. 2066L.

Mueller, W. M. (Mar. 1961), Reduction of beam noisiness by means of a potential minimum away from the cathode, Proc. IRE 49, p. 642.

Ohkoshi, T., and S. Okamura (June 1960), Proposal for a new method of calculation on the noise-reduction mechanism of the potential-minimum place, p. 423, Proc. of The International Congress on Microwave Tubes, Munich.

Pantell, R. H. (June 1960), Electrostatic electron beam couplers, p. 385, Proc. of The International Congress on Microwave Tubes, Munich.

Pease, M. C. (June 1961), transduction of noise. Theory of a generalized traveling-wave coupler, JAP 32, p. 1145.

Peter, R. W. (Dec. 1958), Low-noise traveling-wave tubes, chapter 5 of book Noise in electron devices (published by Technology Press and John Wiley and Sons).

Peter, R. W., Present status of low-noise traveling-wave tubes and future possibilities, presented at Symposium on Reconnaissance at The Johns Hopkins University, presented on November 9, 1961.

Pollack, M. A. (May 1962), Noise and the potential minimum at high frequencies, IRE Trans. ED-9, p. 316.

Russell, C. R. (June 1960), The space-charge wave beam parametric amplifier, p. 348, Proc. of The International Congress on Microwave Tubes, Munich.

Sturrock, P. A. (June 1960), Parametric refrigeration-a mechanism for removal of noise from the slow wave of an electron beam, p. 406, Proc. of The International Congress on Microwave Tubes, Munich.

Van Duzer, T., and J. R. Whinnery (June 1960), Study of noise in crossed-field electron guns, p. 425, Proc. of The International Congress on Microwave Tubes, Munich.

Vehn, R. E., and R. W. Peter (to be published), Travelingwave tube with $1.5 \mathrm{db}$ noise figure in UHF band, Proc. IRE 1963, Letter to the Editor.

Veith, W. (June 1960), Eine Ablenkverstarkerrohre fur Mikrowellen, p. 369, Proc. of The International Congress on Microwave Tubes, Munich.

Vivian, W. E. (June 1960), Transport of noise at microwave frequencies through a space-charge-limited diode, JAP 31, p. 957.

Vlaardingerbroek, M. T. (June 1960), Comparison of noise in microwave triodes and in electron beams, p. 399, Proc. of The International Congress on Microwave Tubes, Munich.

Wade, G. (May 1961), Low-noise amplifiers for centimeter and shorter wavelengths, Proc. IRE 49, p. 880.

Wade, G., R. J. Briggs, and L. Lesensky (Mar. 1962), Lownoise beams from tunnel cathodes, JAP 33, p. 836.

Wessel-Berg, T., K. Blotekjaer (Sept. 1962), Minimum noise temperature of dc-pumped transverse-wave electron beam amplifiers, IRE Trans. ED-9, p. 388.

Whinnery, J. R. (Oct. 1960), High-frequency effects of the minimum on noise, IRE Trans. ED- $\boldsymbol{\gamma}$, p. 218.

Yadavalli, S. (June 1961), Low-noise electron guns and the 6L6 effects, Proc. IRE 49, p. 1098.

Yariv, A., and R. Kompfner (Mav 1961), Noise temperature in distributed amplifiers, IRE Trans. ED-8, p. 207.

Zacharias, A., and L. D. Smullin (July 1960), Noise redetiuon in electron beams, IRE, Trans. ED-y, p. 172. 


\section{Developments in Semiconductor Devices in the United States for the Period 1960-1963}

\section{A. van der Ziel*}

During the period 1960-1963 many existing devices were perfected. Early devices such as fieldeffect transistors became attractive for the first time. Devices such as tunnel diodes received less attention than for the previous 3 -year period, whereas varactor diodes gained prominence as reliable frequency multipliers. Considerable progress was made in the field of integrated circuitry.

New devices such as the thin film transistors and incoherent and coherent infrared radiators were developed. It is believed that the many possible forms of laser diodes will have a considerable future.

The list of references contained in this review is only representative for the topics under discussion and is by no means complete.

\section{Transistors}

Transistors with cutoff frequencies of $1 \mathrm{Gc} / \mathrm{s}$ are presently commercially available. Transistors with cutoff frequencies of 2 to $3 \mathrm{Gc} / \mathrm{s}$ are in the development stage.

Metal-base transistors, based on the relatively long mean free path for hot electrons in metals have been proposed. In these devices the semiconductor base is replaced by a thin metal layer [Geppert, 1962].

\section{Heterojunctions}

Abrupt monocrystalline junctions between two different semiconductor materials of nearly equal lattice spacing can be made by epitaxial deposition of the one material on the other substrate [Anderson, 1960]. Ge-GaAs heterojunctions are an example. Such junctions open up possibilities for new types of devices.

\section{Solar Cells}

It has been found that silicon $n$ on $p$ base cells can tolerate greater integrated radiation fluxes than $p$ on $n$ base cells. GaAs cells appear to be even more resistant to the effects of proton and electron irradiation [Loferski, 1963].

\section{Tunnel Diodes}

There is a certain amount of interest in tunnel diode amplifiers for UHF and microwave frequencies [Yariv, 1961] and in tunnel diode oscillators [Sterzer, 1961].

*University of Minnesota, Minneapolis, Minn.
The use of tunnel diodes in ultra-high-speed switching circuits is handicapped by the bilateral character of the device but some progress is being made toward their utilization in computer circuitry [Sims, 1961'.

The tunnel diode shows considerable promise as a low-noise mixer. The negative resistance region is not beneficial for low-noise operation; the lowest noise figure is obtained when this region is missing [Sterzer, 1962] (the so-called "back diodes").

\section{Varactor Diodes}

Varactor diodes find at present limited use in low-noise up-converters and in low-noise parametric amplifiers. In the latter case low amplifier noise temperatures are obtained by cooling the idler circuit [Kurokawa, 1961].

Varactor diodes are becoming more and more important in frequency multiplier circuits. They provide crystal-controlled oscillator power in the $3 \mathrm{Gc} / \mathrm{s}$ and $9 \mathrm{Gc} / \mathrm{s}$ microwave bands comparable with the power available from low-power klystrons. Reasonable efficiencies can be obtained [Johnson, 9960].

A low-noise low-frequency varactor-diode amplifier was developed [Biard, 1963].

\section{Field-Effect Transitors}

Stable low-noise field-effect transistors have been developed during the last few years and these devices have attracted considerable interest. The noise behavior of these low-noise units is limited by the thermal noise generated in the conducting channel [van der Ziel, 1962; and van der Ziel, 1963].

A CdS polycrystalline field-effect transistor with insulated gate has been developed [Weimer, 1962]. If the stability problem can be overcome, this would be the first semiconductor amplifying device that does not need single crystal material for its fabrication.

\section{Integrated Circuits}

A considerable development is presently under way in integrated electronics [Lesk, 1960; Swan, 1961; and Wallmark, 1962]. More and more integrated circuits are becoming commercially available. The practical objectives aimed at are the following:

1. Increased capabilities per unit weight and per unit volume.

2. Size and weight reduction.

3. Increased reliability and reduced maintenance.

4. Improved power utilization.

5. Reduced cost. 


\section{Tunnel Emission Devices}

Metal-metal-oxide-metal-semiconductor transistors, have been studied [Spratt, 1961]. It was at first believed that the emission through the oxide layer was of the tunnel emission type and that the hot electrons passed through the metal base layer to be collected by the metal-semiconductor junction. Presently it is held that the emission, at least at room temperature is of the Schottky thermionic type involving thermionic emission from traps [Mead, 1962]. It is also held that in many units the current flow is through pinholes and that the transistor-like device operates more or less as a field-effect transistor [Hall, 1961-1962]. This does not exclude the possibility of constructing a true hot electron transistor, of course.

\section{Radiating Diodes, Lasing Diodes}

Many junctions, when biased in the forward direction, show (infrared) light emission due to hole-electron recombination radiation. The wavelength of the emitted light is generally somewhat smaller than the energy gap and depends somewhat on the operating temperature and the operating current. GaAs diodes are a good example of such devices [Pankove, 1962a]. Because of the short lifetime of the minority carriers $\left(\sim 10^{-10}\right.$ sec $)$ microwave modulation is possible [Pankove, 1962b].

At sufficiently large forward current densities the junctions exhibit laser action, resulting in a coherent infrared radiation of much narrower spectral width than the incoherent radiation. The effect has been observed in GaAs [Hall, 1962] at $8400 \AA$ and in other crystals such as InAs at 31,000 $\AA$. By using compounds such as $\mathrm{Ge}_{x} \operatorname{In}_{1-x} \mathrm{As}$ it should be possible to obtain coherent radiation at any wavelength between $8400 \AA$ and $31,000 \AA$. Other mixtures have similar interesting possibilities.

\section{References}

Anderson, R. L. (July 1960), Germanium-gallium arsenide heterojunctions, IBM Journal 4, 283-287.

Biard, J. R. (Feb. 1963), Low-frequency reactance amplifier, Proc. IEEE 51, 298-303.

Geppert, D. V. (June 1962), A metal-base transistor, Proc. IRE 50, 1527-1528.

Hall, R. N. (1961-1962), Current gain in metal-insulator tunnel triodes, Solid-State Electron. 3, 320-322.

Hall, R. N., G. E. Fenner, J. D. Kinsley, T. J. Solty, and R. O. Carlson (Nov. 1962), Coherent light emission from GaAs junctions, Phys. Rev. Letters 9, 366-368.

Johnson, K. M. (Sept. 1960), Large signal analysis of a parametric harmonic generator, IRE Trans. MTT-8, $525-532$.

Kurokawa, K., and M. Uenohara (May 1961), Minimum noise figure of the variable capacitance amplifier, Bell System Tech. J. 40, 695-722.

Lesk, A., N. Holonyak, R. W. Aldrich, J. W. Brouilette, and S. K. Ghandi (Nov. 1960), A catagorization of solid state device aspects of microsystems electronics, Proc. IRE 48, 1833-1841.

Loferski, J. J. (May 1963), Recent research on photovoltaic solar energy converters, Proc. IEEE 51, 667-674.

Mead, C. A. (Dec. 1, 1962), Electron transport mechanisms in thin insulating films, Phys. Rev. 128, 2088-2093.

Pankove, J. I. (Oct. 1962a), Tunneling-assisted photon emission in gallium arsenide PN junctions, Phys. Rev. Letters, $283-285$.

Pankove, J. I. (Sept. 1962b), A light source modulated at microwave frequencies, Proc. IRE 50, 1976-1977.

Sims, R. C., E. R. Beck, V. C. Kamm (Jan. 1961), A survey of tunnel diode digital techniques, Proc. IRE 49, 136-146.

Spratt, J. P., R. F. Schwarz, and W. M. Kane (Apr. 1, 1961), Hot electrons in metal films; injection and collection, Phys. Rev. Letters 6, 341-342.

Sterzer, F., and D. E. Nelson (Apr. 1961), Tunnel diode microwave oscillators, Proc. IRE 49, 744-753.

Sterzer, F., and A. Presser (Mar. 1962), Stable low noise tunnel diode frequency converters, RCA Rev. 23, 3-28.

Swan, J. J. (Feb. 1961), Circuit considerations relating to microelectronics, Proc. IRE 49, 420-426.

van der Ziel, A. (Aug. 1962), Thermal noise in field-effect transistors, Proc. IRE 50, 1808-1812.

van der Ziel, A. (Mar. 1963), Gate noise in field-effect transistors at higher frequencies, Proc. IEEE 51, 461-467.

Wallmark, J. T., and S. M. Marcus (Mar. 1962), Minimum size and maximum packing density of non-redundant semiconductor devices, Proc. IRE 50, 286-298.

Weimer, P. K. (June 1962), The TFT - a new thin film transistor, Proc. IRE 50, 1462-1469.

Yariv, A., and J. S. Cook (Apr. 1961), A noise investigation of tunnel diode microwave amplifiers, Proc. IRE 49, 739743 .

\section{Parametric Devices}

R. Rafuse*

\section{Parametric Amplifiers and Other Small- Signal Devices}

In the period 1960-1963 parametric circuits have been extensively developed. Perhaps the most important breakthrough was the operation of parametric amplifiers at liquid helium temperatures. Blake [1963] and others at M.I.T. Lincoln Laboratories reported $10^{\circ} \mathrm{K}$ excess noise temperature at L-band and Hanson, Fink, and Uenohara [1963] at BTL reported a $2{ }^{\circ} \mathrm{K}$ amplifier temperature (exclusive of input losses) at C-band. In both cases the

\footnotetext{
*M.I.T.-R.L.E., Cambridge, Mass.
}

diodes were point-contact GaAs varactors of the Sharpless [1961] type. Parametric amplifiers of this type are more than competitive with masers. They have wider bandwidth capabilities, higher dynamic range, simpler cryogenics (not temperature sensitive, as are masers), no magnetic field requirements and equivalent noise performance.

The problem of bandwidth in parametric amplifiers and frequency converters has been attacked by Kuh [1962] and Helgesson [1962] with the result that limits on bandwidth and gain-bandwidth have been derived. These limits are fundamental in character and do not necessarily give synthesis schemes for good approximations with finite networks. Continuing experimental work by Gliden and Matthaei 
[1961], Johnson [1961], Little [1961], Schaffner and Voorhaar [1961], and Vincent [1961] and many others has demonstrated that wideband amplifiers and frequency converters can be designed and constructed.

A fairly complete analysis of the various smallsignal devices has been carried out and compiled by Penfield and Rafuse [1962]. They cover the various upconverters, downconverters, and parametric amplifiers for both noise figure and gain. The case of the degenerate parametric amplifier is covered in some detail with particular attention paid to its performance with various detectors. In particular, as de Jager and Robinson [1961] have also shown, the "radiometric" noise figure does not give the proper signal-to-noise ratio for radiometers when written in terms of the post-detector fluctuations; a degenerate parametric amplifier is a factor of $\sqrt{2}$ worse in performance (in a radiometer) than would be predicted from simple noise figure measurements.

The maximum frequencies at which parametric amplification with low noise can be obtained have not risen appreciably during the past three years. Several efforts are now under way to develop 35 Gc/s amplifiers, but the necessary breakthrough in diode cutoff frequency is just beginning. Occasional GaAs point-contact units show cutoff frequencies of $1000 \mathrm{Gc} / \mathrm{s}$, but very recent developments with InSb show great promise. The first InSb varactors to be made have cutoff frequencies as good as the best GaAs units and the next three years may see the advent of millimeter-wave varactor parametric amplifiers.

Interest is now developing in the double-sideband up-converter as a convenient means for achieving ultra-low noise audio- and video-frequency amplification. Analysis of the difficult noise and gain characterization is being carried out at M.I.T. Optimizations of the two-output interface between the upconverter and the following amplifier-synchronous detector combination are being considered with respect to achieving the best noise performance.

There are many other problems under investigation including low-frequency (below the signal) pumping in parametric amplifiers, phase stability in parametric amplifiers and upconverters, and dynamic range. The problem of dynamic range has been severe until very recently. It is now recognized that extremely high dynamic ranges (in excess of $140 \mathrm{db}$ ) can be obtained by suitable varactor circuits. A quick analysis of the technique can be found in the work by Penfield and Rafuse [1962] and indicates that amplifier and receiver technology has seen a millionfold decrease in susceptibility to distortion and cross-modulation effects.

\section{Frequency Multipliers}

Within the past 3 years, all-solid-state microwave power sources have become an operating reality. Solid-state power outputs of $1 \mathrm{w}$ at X-band are now attainable with $5 \mathrm{w}$ at L-band already available. In fact, transistor technology has probably been pressed hardest by the demand for the high power at VHF necessary to drive varactor multiplier chains well up into the microwave region. Reports such as the one by Baldwin, Collins, Johnson, and Priest [1963] of $50 \mathrm{mw}$ at $13.3 \mathrm{Gc} / \mathrm{s}$ are common.

Theoretical analyses now exist which make rational design of frequency multipliers possible. Diamond [1961] and Penfield and Rafuse [1962] have derived the equations for charge-controlled frequency multipliers and dividers. The efficiencies, power outputs, and input and load impedances for many multipliers, up to and including the octupler, are given as functions of signal frequency, diode cutoff frequency, breakdown voltage and minimum junction capacitance. It was shown that nonoverdriven abruptjunction multipliers of orders higher than the doubler must have "idling" currents flowing at one or more intermediate harmonics.

The graded-junction doubler was analyzed by Greenspan [1962] and found to be somewhat less efficient and of considerably less $(1 / 2)$ power handling capability. However, very recent results by Davis [1963] indicate that the overdriven varactor multipliers, utilizing the failure of the forward-conduction mechanism at high frequencies, can handle much more power than the nonoverdriven multipliers and with a rise in efficiency. Perhaps the most important result occurs with the graded-junction which, in the overdriven case, can have a higher efficiency (at least as a doubler) than the equivalent abrupt junction.

The problem of bandwidth in frequency multipliers is still essentially unsolved. A first step in the problem, an analysis of the "bandwidth" limits of an abrupt-junction doubler is now under examination at M.I.T. The word "bandwidth" here is of a much more restrictive sense than normally used in linear circuits. It refers to the maximum range of frequencies over which the driving source for the doubler may be slowly tuned without appreciable degradation in efficiency. No attempt at any concept of "instantaneous bandwidth" has been made for such nonlinear devices.

Spurious signals in multiplier chains still remain a serious problem. McDade [1962] has carried out a simple analysis of one important mechanism with good results experimentally. However, other mechanisms of more complicated nature still produce spurious outputs and have to be dealt with largely on an experimental basis, circuit by circuit.

\section{References}

The amount of literature, both company-produced and journal articles, on parametric amplifiers and multipliers has grown so rapidly that an overall coverage is virtually impos sible. The references given here are necessarily incomplete, but will serve as a relatively thorough introduction to the field.

Baldwin, L. D., F. P. Collins, S. L. Johnson, and W. Priest (Feb. 1963), Operating characteristics and design criteria of an all solid-state $13.3-\mathrm{Gc} 50-\mathrm{mw}$ microwave source, Int'l Solid-State Circuits Conference, Digest of Technical Papers, pp. 50-51.

Blackwell, L. A., and K. L. Kotzebue (1961), Semiconductordiode parametric amplifiers, (Prentice-Hall, Inc., Englewood Cliffs, N.J.). 
Blake, C., L. W. Bowles, E. P. McCurley, and J. A. Nutall (Jan. 1, 1963), Helium-cooled L-band parametric amplifier, Applied Physies Letters II, No. 1, pp. 17-19.

Breon, R. K. (June 1961), The effects of idlers on varactor up-converters, S. B. Thesis, Department of Electrical Engineering, M.I.T., Cambridge.

Davis, J. A. (June 1963), The forward driven varactor frequency doubler, S. M. Thesis, Department of Electrical Engineering, M.I.T., Cambridge.

deJager, J. T., and B. J. Robinson (July 1961), Sensitivity of the degenerate parametric amplifier, Proc. IRE, 49, 12051206.

Diamond, B. L. (Mar. 1963), Some results for higher-order varactor frequency multipliers, M.I.T. Lincoln Laboratory Group Report 47G-5, Lexington, Mass.

Gilden, M., and G. L. Matthaei (Apr. 1961), A nearly optimum wide-band degenerate parametric amplifier, Proc. IRE, 49, 833-834.

Gilden, M., and G. L. Matthaei (Nov. 1961), Practical design and performance of nearly optimum wide-band degenerate parametric amplifiers, IRE Trans. on Microwave Theory and Techniques MTT-9, 484-490.

Greene, J. C., and E. W. Sard (Sept. 1960), Optimum noise and gain-bandwidth performance for a practical one-port parametric amplifier, Proc. IRE, 48, 1583-1590.

Greene, J. C., and W. D. White, and R. B. Adler (Apr. 1961), Radar sensitivity with degenerate parametric amplifier front end, Proc. IRE 49, 804-807.

Greenspan, M. (June 1962), The graded-junction varactor frequency doublers, S. M. Thesis, Department of Electrical Engineering, M.I.T.

Hanson, D. C., H. J. Fink, and M. Venohara (Feb. 1963), Varactor-diode amplifier at liquid helium temperature, Int'l Solid-State Circuits Conference, Digest of Technical Papers, pp. 54-55.

Helgesson, A. L. (Aug. 1962), Gain-bandwidth limitations of balanced three-frequency parametric amplifiers, Sc.D. Thesis, Department of Electrical Engineering, M.I.T., Cambridge.
Hyltin, T. M., and K. L. Kotzebue (Jan. 1961), Solid-state microwave source from reactance-diode harmonic generators, IRE Trans. on Microwave Theory and Techniques MTT-9, 73-78

Johnson, K. M. (Dec. 1961), Broad-band S-Band parametric amplifier, Proc. IRE 49, 1943.

Kuh, E. S. (Jan. 1962), Theory and design of wide-band parametric converters, Proc. IRE 50, 31-38.

Kuh, E. S., and J. D. Patterson (June 1961), Design theory of optimum negative-resistance amplifiers, Proc. IRE 49, 1043-1050.

Kurokawa, K., and M. Venohara (May 1961), Minimum noise figure of the variable-capacitance amplifier, Bell System Tech. J. 40, 695-722.

Little, A. G. (Apr. 1961), A wide-band single-diode parametric amplifier using filter techniques, Proc. IRE 49, 821-822.

Matthaei, G. L. (Jan. 1961), A study of the optimum design of wide-band parametric amplifiers and up-converters, IRE Trans. on Microwave Theory and Techniques MTT-9, $23-38$.

MeDade, J. C. (Jan. 1962), Jump phenomena in varactor diode circuits, Diamond Ordnance Fuze Laboratories Report TR-1008.

Penfield, Jr., P. and R. P. Rafuse (1962), Varactor applications (M.I.T. Press, Cambridge, Mass.).

Schaffner, G., and F. Voorhaar (Apr. 1961), A nondegenerate S-band parametric amplifier with wide bandwidth, Proc. IRE 49, 824-825.

Sharpless, W. M. (Jan. 1961), Gallium Arsenide Point Contact Diodes, IRE Trans. on Microwave Theory and Techniques M'TT-9, 6-10.

Uhlir, A., Jr. (July 1962), Similarity considerations for varactor multipliers, Microwave J. 5:

Vincent, B. T., Jr. (Nov. 1961), A C-band parametric amplifier with large bandwidth, Proc. IRE 49, 1682.

Youla, D. C., and L. I. Smilen (1960), Optimum negativeresistance amplifiers, pp. 241-318, Proceedings of the Polytechnic Institute of Brooklyn Symposia 10, Polytechnic Institute of Brooklyn, Brooklyn, N.Y.

\section{Millimeter-Wave Techniques}

\section{A. Karp* and J. Allison*}

\section{Introduction}

In the past 3 years, the number of people engaged in millimeter-wave research, development, production and sales, and the number and performance of different devices developed, have been very much greater than in the previous 3-year period. However, the number of essentially new ideas has not increased proportionately. Moreover, workers in the field are aware that the demand for their products remains discouragingly low, perhaps in a vicious cycle in which low demand keeps prices high and vice versa. A recent example is the shelving of plans by the Bell System for a cross-country millimeter-wave "pipeline" when it was found to be cheaper to install low-frequency coaxial cables, albeit in the vast multiplicity needed for the same total bandwidth the "pipeline" would have provided. New, essential applications, where only millimeter waves can do the job, are urgently desired.

The most recent, and broadest, conference in this field was held in January 1963, at Orlando, Fla. (Some of the papers presented are represented in this

*Stanford University, Stanford, Calif. report.) The most inclusive survey paper available is Coleman's [Coleman, 1963], covering the state of the art up to the opening of this conference.

\section{Generation; Amplification}

\section{Conventional Tubes}

Progress in the development of magnetrons, klystrons, and traveling-wave tubes towards higher performance and frequency has been due to the refinement of mechanical techniques and electron optics, rather than the introduction of essentially new concepts. Increased power output, as well as frequency, is largely a result of new, higher beam voltage levels, as predicted in a millimeter-wave tube survey paper [Karp, 1960] available at the opening of the present report period. A number of simpler tubes have been commercially available for some time [Serchunk, 1962]. A noninclusive sampling of recent developments follows, and is an index of current trends.

A $70 \mathrm{Gc} / \mathrm{s}$ reflex klystron with $1 \mathrm{w}$ output was produced at Varian Associates (private communication). Development of millimeter-wave coaxial mag- 
netrons [Olson and von Ohlsen, 1961] is being carried on by Westinghouse (private communication), but the S.F.D. Company is now leaning towards the inverted magnetron (private communication). Ingenious helix support methods contributed to the success of a half-watt CW helix traveling wave amplifier (T.W.A.) in the 50 to $60 \mathrm{Gc} / \mathrm{s}$ region [McDowell, 1960; Melroy, 1961]. Workers at Watkins-Johnson have managed to focus beams through 0.005 in. I.D. helices intended for low-noise T.W.A.s at 70 to $85 \mathrm{Gc} / \mathrm{s}$ (private communication). At the level of tens of milliwatts, production of backward wave oscillators (BWO's) with the simple two-dimensional slotted-sheet structure-usually photo-etched-continues at several firms [Melroy, D. O., 1961]. The most recent entries are Sperry's with a present upper limit of $110 \mathrm{Gc} / \mathrm{s}$ at $4 \mathrm{Kv}$ [Noland et al., 1963].

At higher levels of power and cost, the folded waveguide (or single-hole-coupled cavity) structure, usually fabricated of stacked disks and washers, is a preferred circuit. It is used in a Varian B.W.O. [Schumacher, 1963] (45 to $77 \mathrm{Gc} / \mathrm{s}, 1.4-8.8 \mathrm{kv}$; up to $11.5 \mathrm{w}$ ) in a Hughes B.W.O. using the third space harmonic $(50$ to $60 \mathrm{Gc} / \mathrm{s}, 5$ to $10 \mathrm{kv} ; 18 \mathrm{w}$ ), and in a power amplifier using the second (51 to $56 \mathrm{Gc} / \mathrm{s}$; $150 \mathrm{w}$ at 30 percent efficiency with depressed collector (private communication)), [Forster et al, 1962; Forster et al., 1962-63; Forster, Haney, 1963].

A structure of simple vanes, formed by multiple slotting, with a round beam tunnel, spark eroded, is used in some newer Hughes oscillators (private communication) [Forster et al., 1962; Forster et al., 1962-63; Forster, Haney, 1963] (50 to $56 \mathrm{Gc} / \mathrm{s}$; 5 to $10 \mathrm{kv}, 5$ to $30 \mathrm{w}$ at $50 \%$ efficiency with depressed collector, and $140 \mathrm{Gc} / \mathrm{s}$, $5 \mathrm{w}$ peak at $25 \%$ duty factor.)

General Electric has a pulsed ( $80 \mathrm{kv}$ at 1 a) amplifier at $35 \mathrm{Gc} / \mathrm{s}$ with $15 \mathrm{kw}$ peak output [Enderby]. The wave structure consists of a tunnel of rings supported between two metal edges. A 1 $\mathrm{kw}, \mathrm{CW}$, coupled-cavity T.W. amplifier at $35 \mathrm{Gc} / \mathrm{s}$ is also reported (private communication). At 95 to $101 \mathrm{Gc} / \mathrm{s}$, Watkins-Johnson have demonstrated 100 $\mathrm{kw}$ peak and $50 \mathrm{w}$ average B.W.O. powers; at 90 to $200 \mathrm{kv}$ (at 3.5-11a.) only moderate disk loading of the waveguide, as in a linear accelerator, is required [Johnson et al., 1962].

\section{Other Traveling-Wave Tubes}

Recently traveling-wave tubes have been studied in which electrons execute periodically structured trajectories inside smooth waveguides. Helical trajectories [Chow, Pantell, 1960] (with a longitudinal magnetic field of the cyclotron resonance value) have not yet shown any ability to work in the millimeter band. There may be an inherent limitation [Dickson et al., 1961]. Cycloidal trajectories, in a region of crossed steady fields, though demonstrated to be useful in the millimeter region by Reddish in England and Guematsu in Japan, have not yet been tried in the United States. The use of sinusoidal trajectories established by periodically reversing externally applied magnetic fields, [Phillips, 1960] however, has led to impressive results in the extra high-voltage domain where the pitch of the magnetic structure is reasonable. The preferred arrangement uses a $\mathrm{TE}_{01}$ circular-electric waveguide concentric with a hollow beam within which electrons oscillate azimuthally. Over $1 \mathrm{Mw}$ peak power was obtained at $16 \mathrm{Gc} / \mathrm{s}$; at 50 to $75 \mathrm{Gc} / \mathrm{s}$, power output is limited by breakdown of the external, pressurized waveguide [Phillips, 1963].

Development of a d-c pumped quadrupole (transverse wave) amplifier for $70 \mathrm{Gc} / \mathrm{s}$ is under way at S.F.D. [Feinstein, 1962].

\section{Other Schemes Using Thermionic Electrons}

The following schemes for generating signals in the range 30 to $3000 \mathrm{Gc} / \mathrm{s}$ generally differ from the foregoing by existing on a laboratory demonstration rather than a device basis. For brevity, discussion will be confined to the schemes demonstrated in the United States since 1960.

In one general category, tight bunches of electrons are formed and accelerated to megavolt levels so that they may excite a structure through which they pass. The structure is required to have a finite coupling, or radiation, resistance at the desired minimum-wave frequencies, which are also harmonics of the bunching frequency. For example, the bunched beam of a $9.3 \mathrm{Gc} / \mathrm{s}-3.5 \mathrm{Mev}$ linear accelerator was undulated by an array of magnets so as to be able to couple to the ordinary waveguide surrounding the beam, and harmonics up to $750 \mathrm{Gc} / \mathrm{s}$ were observed [Mallory et al., 1963]. (When the waveguide itself is sinuous, it is not necessary to undulate the beam (private communication). Bunched beams have also been used to excite TM $_{\text {Onm }}$ and other cavities [Sirkis et al., 1961]. Of much interest is the excitation of Cerenkov radiation in various media surrounding the beamusually dielectrics or ferrite [Rosenbaum, Coleman, 1963; Coleman, Enderby, 1960; Hakki, Krumme, 1961; Erteza, Newman, 1962; Jelley, 1962]. When such bunches are annihilated [Hakki, Coleman, 1961] or undergo other transitions, they can be made to radiate some of their energy. Sinusoidal deflection modulation of an unbunched beam of finite diameter causes bunches to appear to an observer watching the beam cross a plane at an angle to the mean velocity. These electrons can couple to the $E$ fields of waves in a dielectric-loaded interferometer oriented at this angle [Baird, Coleman, 1963].

In another category, Weibel's scheme for getting a pulse of radiation by quickly applying a strong magnetic pulse to a trapped electron cloud has been demonstrated [Dressel et al., 1962].

\section{Harmonic Generation and Parametric Devices}

The mixing of low-frequency signals, or the generation of their harmonics, in nonlinear media has long been a much studied means of obtaining higherfrequency signals. Extension of results to the 
millimeter range, however, has been very difficult [Coleman]. A possible exception, at least at low power levels, is the use of a point-contact diode as the nonlinear element, [Ohl et al., 1959; Wentworth et al., 1963]. With a proper choice of base and whisker materials, production of a usable signal at a frequency about $400 \mathrm{Gc} / \mathrm{s}$ is not considered exceptional.

Nonlinear-capacitor, semiconductor junctions are perhaps the next contender [Heilmeier, 1960; DeLoach, 1960]. The list of other nonlinear media under study includes gaseous discharges, electron swarms (as in magnetrons), magnetic materials, ferroelectrics, superconductors and field emitters [Coleman]. So far only a few reductions to practice at millimeter wavelengths have been reported [Ayers, 1959; Heller, 1961; Moore, 1962; Knight, Walsh, 1962].

\section{Masers, Quantum Devices, Etc.}

In reviewing progress in the generation or amplification of millimeter waves under this heading, mention may be made of the Esaki diode: Burrus and Trambarulo [Burrus, 1960; Burrus, Trambarulo, 1961] demonstrated that with suitable materials signals of frequency higher than 100 $\mathrm{Gc} / \mathrm{s}$ - albeit at very low power level-could be generated. Shaw's scheme for getting a pulse of radiation by applying a rapidly rising, strong magnetic pulse to a small sphere of single-crystal ferrimagnetic material, (YIG) has been tested. The energy is stored in the precessional motion of electron spins. Operation beyond $50 \mathrm{Gc} / \mathrm{s}$ with a peak power of tenths of a watt has been reported (private communication) [Elliott et al., 1961]. Attempts to extend the microwave frequencies observed in the beating of intense optical radiation within, or at the surface of, various media are continuing [Coleman].

Several solid-state masers, based on paramagnetic ions in a suitable host crystal, have been reported operational in the millimeter band [Coleman, Momo, et al., 1960; Foner, 1960; Carter, 1961; Devor, 1963]. The modes of operation include those requiring pulsed and steady magnetic fields, and pumping at lower microwave, higher microwave, and optical frequencies. Stimulated emission at the $88.63 \mathrm{Gc} / \mathrm{s}$ transition in hydrogen cyanide gas has also been observed [Marcuse, 1961; Barnes, Maley, 1961]; Marcuse's apparatus, for example, included a Fabry-Perot resonator into which the gas is admitted via an electrostatic state selector.

\section{Passive Components}

\section{Transmission Systems}

The various types of metal-walled waveguide now used at millimeter wave frequencies, for example $\mathrm{TE}_{10}$ mode circular guides and oversized guides, were mostly developed prior to 1960 and more recent work has been concerned with increasing their oper- ating frequencies to above $100 \mathrm{Gc} / \mathrm{s}$ [Martin, Karbowiak, 1960; Valenzuela, 1963; King, 1963]. The usefulness of other guiding structures, for example dielectric-loaded, parallel-plane and trough lines, [Cohn, 1960; Cohn et al., 1960; Tischer, 1963] and block-loaded guides [Mims, 1960] have also been studied. Single-wire lines, both coated and uncoated [King, Wiltse, 1962] and double-wire lines [Ishii, 1961] have been used successfully at these frequencies.

Several millimeter-wave optical transinission systems have been studied recently. Sobel et al. [Sobel et al., 1961], use horn antennas in conjunction with large diameter phase-reversing Fresnel zoneplates to obtain transmission losses of only $2 \mathrm{db}$ over $55 \mathrm{ft}$ at $1.4 \mathrm{~mm}$ wavelength. Transmission at $4.25 \mathrm{~mm}$ wavelengths between parabolic antennas with separations up to $100 \mathrm{ft}$ gives losses about twice those obtained by Sobel [Fellers, 1962]. Goubau [Goubau, Schwering, 1961; Christian, Goubau, 1961] has investigated a system of horns and periodically spaced phase-transforming lenses to guide a beam with theoretically arbitrarily small loss. In practice the attenuation can be less than $1 \mathrm{db}$ per $1000 \mathrm{ft}$ at $8 \mathrm{~mm}$ wavelengths.

Application of quasi-optical prin ciples to individual components is represented by an attenuator which couples the evanescent waves near the oblique faces of two prisms with variable separation [Raker, Valenzuela, 1962; Taub et al., 1963]. The use of gratings has also been reported [Mallory et al., 1963].

\section{Resonators}

Fabry-Perot resonators, while not new in principle, have been intensively studied recently both as interferometers, and with a view to integrating them into other optical and semioptical systems [Culshaw, 1960; 1961; Fox, Li, 1961; Zimmerer, 1962; Culshaw, 1962]. Confocal resonators, because of their lower diffraction losses for a given size, may become important in the millimeter wave region [Boyd, Gordon, 1961; Boyd, 1961; Boyd, Kogelnik, 1962].

\section{Ferrite Devices}

Thanks to new materials (such as hexagonal ferrites, whose anisotropy fields facilitate getting ferromagnetic resonance at the higher frequencies) as well as to the extension of centimeter-wave principles, isolators, circulators, etc., have been developed for frequencies up to $100 \mathrm{Gc} / \mathrm{s}$ [Thaxter, Heller, 1960; Barnes, 1961; Rodique, 1963; Harrison et al., 1963]. A representative commercial 4-port device (Watkins-Johnson) may be used as a circulator, isolator, band-pass or -reject filter, etc., at 70 to $85 \mathrm{Gc} / \mathrm{s}$. It uses two 0.014 in. diam. YIG spheres in crossed waveguide. Applied magnetic induction is 30 kilogauss and residual insertion loss is under $2 \mathrm{db}$.

\section{Detectors}

Until recently, the only practical detectors with response covering infrared as well as millimeter wave- 
lengths were thermal types [DeWaard, Wormser, 1959; Goodwin, Jones, 1961; Long, Rivers, 1961; Arnold et al., 1963]. More recently, an InSb photodetector covering this range has been developed in the U.K. [Putley, 1960] and the process believed to be responsible for its operation is discussed by Rollin [Rollin, 1961]. As a low-level mixer and video detector for the lower millimeter wavelengths, the crystal diode is most frequently used. Gallium arsenide has been demonstrated to have superior properties to either silicon or germanium for this purpose [Sharpless, 1961]. Application of d-c bias can increase the gain and sensitivity while reducing the noise [Ishii, Brault, 1962]. Tunnel diodes in the form of gallium- $n$ germanium point contacts, operated on the reverse portion of the $I \mathrm{~V}$, curve have vielded good performance up to at least $300 \mathrm{Gc} / \mathrm{s}$ [Burrus, 1963].

\section{References}

Arams, F. R., et al. (Jan. 1963), Pack tunable T.W. maser and a maser radiometer for the $8 \mathrm{~mm}$ Band, Presented at The Millimeter and Submillimeter Conference, Orlando, Fla., to appear in Trans. IEE, MTT-II.

Arnold, R. 'T., et al. (Jan. 1963), A broadband pyroelectric detector, Presented at The Millimeter and Submillimeter Conference, Orlando, Fla., to appear in Trans. IEE, MTT-II.

Ayers, W. P. (Jan. 1959), Millimeter wave generation experiment utilizing ferrites, IRE Trans. MTT-y, p. 62.

Baird, J. R., P. D. Coleman, (Jan. 1963), Bunching of an electron beam by deflection modulation, Presented at The Millimeter and Submillimeter Conference, Orlando, Fla., to appear in Trans. IEE, MTT-II.

Barnes, C. E. (Nov. 1961), Broad-band isolators and variable attenuators for millimeter wavelengths, IRE Trans. MTT-9, p. 519.

Barnes, F. S., and D. Maley (Mar. 1961), Beam maser for 3 millimeters uses hydrogen cyanide, Electronics 34, p. 45.

Boyd, G. D., J. P. Gordon, (1961), Confocal multimode resonator for millimeter through optical wavelength masers, Bell System Tech. J. 40, p. 489.

Boyd, G. D. (1961), Advances in quantum electronics, ed. J. R. Singer, p. 308 (Columbia University Press).

Boyd, G. D., and Kogelnik (July 1962), Generalized confocal resonator theory, Bell System Tech. J. 41, p. 1347.

Burrus, C. A. (Dec. 1960), Millimeter wave Esaki diode oscillators, Proc. IRE 48, p. 204.

Burrus, C. A., and R. Trambarulo, (June 1961), A millimeterwave Esaki diode amplifier, Proc. IRE 49, p. 1075.

Burrus, C. A. (Jan. 1963), Backward diodes for low-level millimeter-wave detection, Presented at The Millimeter and Submillimeter Conference, Orlando, Fla. to appear in Trans. IEE, MT'T-II.

Carter, D. L. (Dec. 1961), A CW solid state, push-pull maser in the 5-6 millimeter wavelength region, J. Appl. Phys. 32, p. 2541.

Chow, K. K., and R. H. Pantell, (Nov. 1960), The cyclotron. resonance backward wave oscillator, Proc. IRE 48, p. 1865 , Nov. 1960

Christian, J. R., and G. Goubau, (May 1961), Experimental studies on a beam waveguide for millimeter waves, IRE Trans. AP-9, p. 256.

Cohn, M. (July 1960), TE modes of the dielectric loaded trough line, IRE Trans. MTT-8, p. 449

Cohn, M., et al. (Sept. 1960), TE mode excitation on dielectric loaded parallel plane and trough waveguides, IRE Trans. MTT-8, p. 545 .

Coleman, P. D., State of the art-background and recent developments - millimeter and submillimeter waves, Stanford University Microwave Lab. Report No. 991, to appear in Trans. IEEE-MTT.
Coleman, P. D., and C. Enderby, (Sept. 1960), Megavolt electronics Cerenkov coupler, J. Appl. Phys. 31, p. $1695(\mathrm{~L})$.

Culshaw, W. (Mar. 1960), High resolution millimeter wave Fabry-Perot interferometer, IRE Trans. MTT-8, p. 182.

Culshaw, W. (1961), Resonators for millimeter and submillimeter wavelengths, IRE Trans. MTT-9, p. 135.

Culshaw, W. (Sept. 1962), Further considerations on FabryPerot type resonators, IRE Trans. MTT-10, p. 331.

DeLoach, B. C. (July 1960), 17.35 and $30 \mathrm{kMc}$ parametric amplifier, Proc. IRE 48, p. 1323.

Devor, D. P. (Jan. 1963), Extension of the laser-pumped ruby maser to millimeter wavelengths, Presented at The Millimeter and Submillimeter Conference, Orlando, Fla., to appear in Trans. IEEE, MIT-II.

DeWaard, R., and E. M. Wormser, (Sept. 1959), Description and properties of various thermal detectors, Proc. IRE 47, p. 1509 .

Dickson, W. L., et al (Nov. 1961), Large signal interaction between a spiraling electron beam and the $\mathrm{TE}_{10}$ rectangular waveguide mode, Proc. IRE 49, p. 1696.

Dressel, H. O., et al. (Sept. 1962), Generation of millimeter radiation by magnetic pulsing of a trapped electron cloud, 4th Int. Congress on Microwave Tubes, Scheveningen, Holland.

Elliott, B. J., et al., Pulsed millimeter-wave generation using ferrites, IRE Trans. MTT-9.

Enderby, C. E., 35 Gc-15 Kw ring-plane amplifier, submitted to Trans. IEEE-ED

Erteza, A., and J. Newman, (May 1962), Cerenkov radiation from electrons traveling in a circle through a dielectric medium, J. Appl. Phys. 33, p. 1864.

Feinstein, J. (1962), Transverse wave tubes for the millimeter band, NAECON Nat. Conf. Proc. 17, Dayton, Ohio.

Fellers, R. F. (May 1962), Millimeter wave transmission by non-waveguide means, Microwave Journal V. p. 80.

Foner, S. (Apr. 1960), CW millimeter wave maser using $\mathrm{Fe}^{3+}$ in $\mathrm{TiO}_{2}$, J. Appl. Phys. 31, p. 742(L).

Forster, D. C., et al. (1962), Linear beam tubes at millimeter wavelengths, NAECON Nat. Conf. Proc. 1, Dayton, Ohio.

Forster, D. C., et al. (1962-3), High Power CW mm-wave amplifier and oscillator, Proc. 4th Inter. Microwave Tube Congress, Holland.

Forster, D. C., and J. S. Haney, (1963), High power mm-wave tubes for aerospace applications, NAECON Conf. Proc., Dayton, Ohio.

Fox, A. S., and T. Li (1961), Resonant modes in a maser interferometer, Bell System Tech. J. 40, p. 453, or Advances in quantum electronics, p. 308, ed., J. R. Singer (Columbia Univ. Press).

Goodwin, D. W., and R. H. Jones (Oct. 1961), Far infrared and microwave detector, J. Appl. Phys. 32, p. 2056(L).

Goubau, G., and F. Schwering (May 1961), On the guided propagation of electromagnetic wave beams, IRE Trans. AP-9, p. 248.

Hakki, B. W., and P. D. Coleman (June 1961), Cerenkov radiation in a dielectric tube waveguide, Proc. IRE 49, p. 1084 .

Hakki, B., and H. Krumme (Aug. 1961), Coherent generation of microwave power by annihilation radiation of a prebunched beam, Proc. IRE, 49, p. 1334.

Harrison, G. R., et al. (Jan. 1963), Millimeter resonance isolators utilizing hexagonal ferrites, Presented at The Millimeter and Submillimeter Conference, Orlando, Fla., to appear in Trans. IEE, MTT-II.

Heilmeier, G. H. (July 1960), Millimeter wave generation by parametric methods, Proc. IRE 48, p. 1326.

Heller, G. S. (Mar. 1961), Antiferromagnetic materials for millimeter and submillimeter devices, J. Appl. Phys. 32, p. 3075.

Isbii, K. (June 1961), Two-wire millimeter-wave surface transmission, Proc. IRE 49, p. 1076.

Ishii, K., and A. L. Brault (July 1962), Noise output and noise figure of miased millimeter-wave detector diodes, IRE Trans. MTT-10, p. 258.

Jelley, J. V. (Oct. 1962), Cerenkov radiation at microwave frequencies, Microwave Journal V, p. 149.

Johnson, H. R., et al. (1962), New transmitting and receiving devices for millimeter wavelengths, NAECON Nat. Conf. Proc. 21, Dayton, Ohio. 
Karp, A. (1960), Millimeter-wave valves, Fortschritte der Hochfrequenztechnik 5, pp. 73-128.

King, A. P. (Jan. 1963), A low-loss waveguide system and components, Presented at The Millimeter and Submillimeter Conference, Orlando, Fla.; to appear in the Trans. IEE, MTT-II.

King, M. J., and J. C. Wiltze (1962), Surface wave propagation on coated or uncoated metal wires at millimeter wavelengths, IRE Trans. AP-10, p. 246, 1962.

Knight, D. J., and D. Walsh (Sept. 1962), Millimeter wave harmonics from a gas discharge, 4th Int. Congress on Microwave Tubes, Scheveningen, Holland.

Long, M. W., and W. K. Rivers (June 1961), Submillimeter wave radiometry, Proc. IRE 49, p. 1024.

Mallory, K. B., et al. (Jan. 1963), A simple grating system for millimeter and submillimeter wavelength separation, Presented at the Millimeter and Submillimeter Conference, Orlando, Fla.; to appear in the Trans. IEE, MTT-II.

Mallory, K. B., et al. (Jan. 1963), Production of submillimeter waves by bunched, relativistic electrons, Presented at the Millimeter and Submillimeter Conference, Orlando, Fla.; to appear in the Trans. IEE, MTT-II.

Marcuse, D. (Nov. 1961), Maser oscillations observed from HCN maser at $88.6 \mathrm{kMc}$, Proc. IRE 49, p. 1706.

Martin, C. A., and A. E. Karbowiak (Feb. 1960), TM waves in submillimetric region, Proc. IRE 48, p. 250.

McDowell, H. L. (Mar. 1960), A half watt CW traveling-wave amplifier for the 5-6 millimeter band, Proc, IRE 48, p. 321.

Melroy, D. O. (Aug. 1961), A 50-milliwatt BWO and 0.5 watt TWT for CW operation at 50-60 kMc. Wescon Convention (San Francisco), Monograph No. 27/4.

Mims, W. B. (May 1960), The block loaded guide as a slow wave structure, Proc. IRE 48, p. 1176.

Momo, L. R., et al. (Feb. 1960), Pulsed field millimeter wave maser, J. Appl. Phys. 31, p. 443(L).

Moore, R. A. (Mar. 1962), Millimeter wave parametric amplification with antiferromagnetic materials, J. Appl. Phys. 33, p. $1274 \mathrm{~S}$.

Noland, J. A., et al. (Jan. 1963), Wide tuning range swept oscillator sources for 48 to 110 Gc., presented at The Millimeter and Submillimeter Conference, Orlando, Fla.; to appear in the Trans. IEE, MTT-II.

Ohl, R. S., et al. (Sept. 1959), Improved diode for the harmonic generation of millimeter and submillimeter waves, Rev. Sci. Inst. 30, p. 765 .

Olson, H. M., and L. H. vonOhlsen (Aug. 1961), The coaxial magnetron, Wescon Convention (San Francisco), Monograph No. 2/1.

Phillips, R. M. (Oct. 1960), The ubitron, Trans. IRE ED-y, p. 231.
Phillips, R. M. (Jan. 1963), The generation of high pulsed power at millimeter wavelengths using the ubitron, presented at The Millimeter and Submillimeter Conference, Orlando, Fla.; to appear in the Trans. IEE, MTT-II.

Putley, E. H. (1960), Proc. Soc. 76, p. 802.

Raker, H. D., and G. R. Valenzuela (Sept. 1962), A doubleprism attenuator for millimeter waves, IRE Trans. MTT10, p. 392, Sept. 1962.

Rodique, G. P. (Jan. 1963), Magnetic materials for millimeter wave application, presented at The Millimeter and Submillimeter Conference, Orlando, Fla.; to appear in the IEE Trans. MTT-II.

Rollin, B. V. (May 1, 1962), Detection of millimeter and submillimeter-wave radiation by free carrier absorption in a semiconductor, Proc. Phys. Soc. 7\%, p. 1102.

Rosenbaum, F. J., and P. D. Coleman (Jan. 1963), Cerenkov radiation in anisotropic ferrites, presented at The Millimeter and Submillimeter Conference, Orlando, Fla.; to appear in the IEE Trans. M'T'T-II.

Schumacher, R. T. (Jan. 1963), Presented at The Millimeter and Submillimeter Conference, Orlando, Fla.; to appear in the IEE Trans. MTT-II.

Serchuk, A. (Oct. 1962), Millimeter tube survey, Microwaves 1, p. 27.

Sharpless, W. M. (Jan. 1961), Gallium-arsenide point-contact diodes, IRE Trans. MTT-9, p. 6.

Sirkis, M. D., et al. (Oct. 1961), Electron beam excitation of a Fabry-Perot interferometer, J. App., Phys. 32, p. 2055(L).

Sobel, F., et al. (Nov. 1961), Quasi-optical surface waveguide and other components for the 100 to 300 Ge region, IRE Trans. MT'T-9, p. 512 .

Taub, J. J., et al. (Jan. 1963), Submillimeter components using oversize quasi-optical waveguide, presented at The Millimeter and Submillimeter Conference, Orlando, Fla.; to appear in the Trans. IEE M'T'T-II.

Thaxter, J. B., and G. S. Heller (Jan. 1960), Circulators at 70 and $140 \mathrm{kMc}$, Proc. IRE 48, p. 110.

Tischer, F. J. (1963), The groove-guide concept, a method for low-loss transmission at mm-waves, presented at The Millimeter and Submillimeter Conference, Orlando, Fla.; to appear in the IEE Trans. MTT-II.

Valenzuela, G. R. (Jan. 1963), Millimeter transmission by oversize and shielded-beam waveguides, presented at The Millimeter and Submillimeter Conference, Orlando, Fla.; to appear in the IEE Trans. MTT-II.

Wentworth, F. L., et al. (1963), Millimeter wave harmonic generators, mixers and detectors, presented at The Millimeter and Submillimeter Conference, Orlando, Fla.; to appear in the IEE Trans. MTT-II.

Zimmerer, R. W. (1962), New wavemeter for millimeter wavelengths, Rev. Sci. Inst. 33, p. 858.

\section{Status of Gas Lasers}

\section{W. R. Bennett, Jr.*}

Since the announcement [Javan, Bennett, and Herriott, 1961] of the first successful helium-neon gas laser in February of 1961, developments in this field have continued to move at a rapid pace. A detailed review of material through December of 1962 has been given previously by the author [Bennett, 1962] and more recent compilations are to be contained in the Proceedings of the Third International Conference on Quantum Electronics [Third International Symposium, 1963] and the Symposium on Optical Masers held at Brooklyn Polytechnic Institute [Optical masers Symposium, 1963].

As of the present writing (May 1963), continuous oscillation has been obtained on over 150 transitions,

*Yale University, New Haven, Conn.
[Javan, Bennett, and Herriott, 1961; Rabinowitz et al., 1962; Patel et al., 1963] ranging from the visible $(0.59 \mu)$ [Gordon et al., 1963] to the far infrared (32.5 $\mu$ ) [McFarlane, 1963]. Oscillation has been obtained in over a dozen gas systems, using at least four different excitation mechanisms. The vast majority of cases has been found in the pure noble gases (or mixtures of noble gases) through use of electron impact as the dominant excitation process. Oscillation has been obtained on some two dozen transitions in the helium-neon system in which near resonant transfer of energy from the $2^{3} \mathrm{~S}$ and $2^{1} \mathrm{~S}$ metastable states of helium has been used in collisions with ground state neon atoms to populate the upper neon maser levels. So far, the helium-neon system has been the only one reported in which laser oscilla- 
tion has been produced through this inelastic collision process. However, and somewhat ironically, oscillation has still not been obtained on the transitions initially proposed in the helium-neon case [Javan, 1959 and 1960]. A somewhat more general excitation method using metastable carriers of energy has been found to involve molecular dissociation. The first of these systems is quite representative and makes use of neon metastables to dissociate ground state oxygen molecules, leaving one constituent atom in the upper maser level [Bennett, $1962 \mathrm{a}, \mathrm{b}$, 1963]. Here the existence of three particles in the final state permits obtaining large transfer cross sections (in the order of $10^{-15} \mathrm{~cm}^{2}$ ) even in cases involving large ( 1 or $2 \mathrm{ev}$ ) energetic resonance discrepancies. Oscillation has since been reported in approximately half a dozen cases involving molecular dissociation [Bennett, 1962a and Patel et al., 1963]. The existence of an anomalous frequency shift in the maser oscillation from the center of the spontaneous emission line is presumably explained by the presence of unidentified molecular absorption bands in the two oxygen masers [Bennett, 1962a and 1963]. Similar difficulties may exist in the other molecular systems, and it seems probable that the noble gas systems are likely to be more suitable for purposes of precise measurement. In contrast to the solid state field, only two cases (both in cesium) have been reported in gas lasers in which optical pumping has been used as an effective excitation process [Rabinowitz et al., 1962 and 1963]. The transitions that have worked through optical pumping have both depended on a fortunate coincidence of the $3889 \AA$ resonance line of helium with one of the resonance lines in cesium. To date, oscillation has only been obtained on atomic transitions and the use of molecular transitions is yet to be explored [Muller et al., 1963].

The gain constants for transitions from analogous excited states vary roughly as the third power of the wavelength in the short wavelength region. Such a rough dependence is to be expected so long as the maser transition is the dominant one from the upper state [Bennett, 1962b], and is at least crudely obeyed through about 3 to $4 \mu$. Hence exponential gain constants $\left(\frac{1}{I} \frac{d I}{d x}\right)$ have been reported ranging from 0.1 per meter at $1.15 \mu$ in neon [Bennett, 1962b] to as high as 10 per meter at $3.5 \mu$ in xenon [Paananen et al., 1963]. No gain measurements have been reported in the extreme long wavelength region as yet; however, the gradual decrease in branching ratio in the far infrared will probably result in considerable departure from the $\lambda^{3}$ dependence. In spite of the smaller branching ratios at extremely long wavelengths, however, many likely possibilities for oscillation exist out to nearly $1 \mathrm{~mm}$ and it appears probable that the optical-microwave gap in coherent sources of oscillation will be closed in the near future. In contrast to the gain dependence on wavelength, the power available varies roughly as the reciprocal of the wavelength and for practical dimensions has been limited to some tens of milliwatts in CW systems. Power outputs of several watts have been obtained on a pulsed basis from the helium-neon system at $1 \mu$ [Byerly et al., 1963]. Some hope exists for obtaining larger power outputs through the use of photodissociation in systems currently being studied [Gould, 1963], and through use of power amplifiers in existing systems.

The only precise studies of the spectral characteristics of gas lasers have been conducted with the strong $1.15 \mu$ transition of neon in the helium-neon system. The gain in this system is so small that extremely high Q cavities are required, with the result that the oscillation frequency is determined by the cavity resonance frequencies to first order and hence varies directly with the dimensions of the laser. The high degree of inherent spectral purity therefore loses much of its practical value except in cases where one is primarily interested in the cavity properties or in cases where negative feedback stabilization signals may be derived. In the heliumneon system, internal beat experiments [Javan et al., 1963] have indicated that the inherent spectral width of the oscillation is less than $2 \mathrm{c} / \mathrm{s}$ and beats between different lasers have indicated a short term stability good to about $20 \mathrm{c} / \mathrm{s}$ under ideal laboratory conditions [Jaseja et al., 1963]. Of more importance for communication purposes, it has been demonstrated [Rabinowitz et al., 1963], that servo mechanisms may be used to lock one gas laser on another to within a few kilocycles on a long term basis. Also, beats between opposite running waves in rotating ring lasers have been used to measure absolute rotation [Macek et al., 1963].

Studies of mode-pulling phenomena in the heliumneon system have shown the existance of a variety of nonlinear frequency-dependent mode-pulling effects which might be used to stabilize the cavity resonances on the center of the Doppler broadened line [Bennett, 1962 and 1963; Gould et al., 1963].

In particular, one such null-balance method should permit absolute stabilization in single mode operation to several kilocycles. [Bennett, 1963: Gould et al., 1963]. The high gain available in the long wavelength region may also permit the construction of gas lasers in which the cavity resonance widths are large compared to the Doppler widths and in which oscillation occurs to first order on the center of the spontaneous emission line see Bennett in TRG final report available from ASTIA.

Theoretical studies of cavity mode properties have been given in references [Boyd and Kogelnik, 1952; Boyd and Gordon, 1961; and Fox and Tingye, 1961] and have been confirmed to at least first approximation by experimental studies in reference [Bennett, 1962; Javan, Bennett, and Herriott, 1961; Javan, Ballik, and Bond, 1962; Herriott, 1962; and Rigrod et al., 1962]. Extensive calculations of the frequency and power dependence on gas laser parameters have been given in references [Bennett, 1962b, 1962c, and 1963; Javan et al., 1962; Lamb, 1963; and Tang and Statz, 1962]. Related experimental studies have been reported 
in references [Bennett, 1962c; Javan et al., 1961; Javan et al., 1962; Rigrod et al., 1962; Paananen et al., 1963; McFarlane et al., 1963; and Javan, 1963].

\section{References}

Bennett, Jr., W. R. (1962a), Applied optics supplement.

Bennett, Jr., W. R. (1962b), Phys. Rev. 126, 580.

Bennett, Jr., W. R. TRG final report for Contract AF33 (657)-8060, available for ASTIA, pp. 38-96.

Bennett, Jr., W. R. W. L. Faust, R. A. McFarlane and C. K. N. Patel (1962), Phys. Rev. Letters 8, 470.

Bloom, Arnold L. (1963) Appl. Phys. Ltrs. 2, 101

Boyd, G. D., and H. Kogelnik (1952), Bell System Tech. J. 41, 1347.

Boyd, G. D., and J. P. Gordon (1961), Bell System Tech. J. 25, 489.

Byerly, E., J. Goldsmith, and W. MeMahan (April 1963), Proceedings of the Symposium on optical masers, Electrochemical society Meetings.

Faust, W. L., R. A. McFarlane, C. K. N. Patel, and C. G. B. Garrett (Feb. 1963), Appl. Phys. Ltrs. 1, 85, 1962; Proceeding of Third International Symposium on Quantum Electronics, Paris

Fox, A. G., and Tingye Li (1961), Bell System Tech. J. 40, 453.

Gordon, E. I., A. D. White (1963), Nature, in press.

Gould, G., and W. R. Bennett, Jr. (May 1963), Proceeding March meeting of Optical Society of America in Jacksonville, Fla.

Gould, G. (1963), Symposium on Quantum Electronics, Paris.

Herriott, D. R. (1962), J. Opt. Soc. Am. 52, 31.

Javan, A. (1959), Phys. Rev. Ltrs. 3, 87.

Javan, A. (1960), Quantum Electronics, pp. 564-571 ed. C. H. Townes (Columbia University Press, New York, N.Y.).
Javan, A. (Feb. 1963), Quantum Electronics Symposium, Paris.

Javan, A., W. R. Bennett, Jr., and D. R. Herriott (1961), Phys. Rev. Letters 6, 106.

Lamb, Jr., W. E. (1963), Phys. Rev. in press.

Macek, W. M., and D. T. M. Davis, Jr. (1963), Appl. Phys. Ltrs. 2, 67.

McFarlane, R. A., C. K. N. Patel, W. R. Bennett, Jr., and W. L. Faust (1962), Proc. IRE 50, 2111.

McFarlane, R. A., W. R. Bennett, Jr., and W. E. Lamb, Jr. (1963), Appl. Phys. Ltrs. in press.

Muller, M. W., A. Sher, R. Solomon, and D. G. Dow (1963), Appl. Phys. Ltrs. 2, 86.

Optical masers symposium (April 1963), Polytechnic Institute of Brooklyn, New York, N.Y. For Proceedings and abstracts, write Microwave Research Institute, 55 Johnson Street, Brooklyn 1, N.Y.

Paananen, R. A., and D. L. Bobroff (1963), Appl. Phys. Ltrs. ק, 99.

Paananen, R. A., C. L. Tang, and H. Statz (1963), Proc. IEEE 51, 63.

Patel, C. K. N., W. R. Bennett, Jr., W. L. Faust, and R. A. MeFarlane (1962), Phys. Rev. Ltrs. 9, 102.

Patel, C. K. N., R. A. McFarlane, and W. L. Faust (1963), Bull. Am. Phys. Soc. 8, 299, Proceedings March 1963 meeting of Optical Society of America, Jacksonville, Florida, Bull. Am. Phys. Soc. 8, 380.

Rabinowitz, P., S. Jacobs, and G. Gould (1962), Appl. Opt. 1, 513 .

Rabinowitz, P., S. Jacobs, and G. Gould (1963), Quantum Electronics symposium, Paris. For proceedings write to Mme Cauchy, 7 Rue de Madrid, Paris 8, France.

Rabinowitz, P., J. LaTourette, and G. Gould (1963), Proc. IEEE 51, 857.

Tang, C. L., and H. Statz (1962), Phys. Rev. 128, 1013.

Third International Symposium (1963), Quantum electronics, Paris. For proceedings write to Mme Cauchy, 7 Rue de Madrid, Paris 8, France.

\section{Noise in Masers}

\section{Hermann A. Haus*}

The role of spontaneous emission as a source of maser noise had been recognized in the study of maser noise at microwave frequencies. These studies also had revealed that spontaneous emission would be the predominant noise in linear amplification at optical frequencies. Part of the recent work on optical maser noise therefore was concerned with refinements of the analysis of spontaneous emission. Because the spontaneous emission output noise power of a linear amplifier within the frequency band B cannot be reduced to less than $h \nu B G$ (where $h$ is Planck's constant, $\nu$ is the frequency at center band, $G$ is the amplifier power gain) it was natural to search for a connection between this minimum noise power and the uncertainty principle. The definition of noise and its relation to coherence of a waveform was also studied. Finally, the first experiments on the frequency stability of optical masers were reported. Preliminary measurements on the amplifier noise have been made.

\section{Spontaneous Emission Noise}

The work on spontaneous emission in masers was concerned with refining the physical models of the

\footnotetext{
*M.I.T.-R.L.E., Cambridge, Mass.
}

active maser medium and the mathematical treatment of the electromagnetic field [Senitzky, 1960, 1961, 1962; Haus and Mullen, 1963]. The complete probability distribution of the signal and noise amplitudes at the output of an optical maser amplifier has been obtained [Louisell, 1963] with the aid of a simple mathematical model for the maser which incorporates the main characteristics of the amplifier. The noise has been shown to be additive Gaussian noise. A study of quantum effects in parametric amplifiers at optical frequencies has arrived at very similar results [Louisell, Yariv, Siegman, 1961; Louisell, Gordon, Walker, 1963]. The similarity of the results is not coincidental. This has been demonstrated by studies which showed that a minimum additive noise is necessary in ideal linear amplifiers [Serber and 'Townes, 1960; Heffner, 1962; Oliver, 1961; Haus and Townes, 1962] in order to satisfy the uncertainty principle. In this connection the studies on the information-theoretical implications of maser noise are also of interest [Gordon, 1962]. Finally, spontaneous emission noise has been shown to set an ultimate limit to the frequency stability achievable in optical maser oscillators [Townes, 1961]. 


\section{Coherence}

The concepts of noise and coherence and their quantitative measures have been used for years in electrical engineering on one hand, and optics on the other hand. The advent of the optical maser put these into new perspective and several papers have appeared that deal with these questions, R. J. Glauber [Glauber, 1963; Glauber, to be published in Phys. Rev.] formulated measures of wave coherence that are consistent with quantum field theory. He defines a set of normalized correlation functions which are equal to or less than unity. A waveform is defined to be perfectly coherent if all correlation functions are equal to unity. These new correlation functions introduced by Glauber have been discussed in their classical limit by Wolf [1963] and further interpretations have been attempted [Sudarshan, 1963].

\section{Measurements}

Measurements on the frequency stability of the beat-note between two axial modes in a gaseous He-Ne optical maser oscillator have been reported [Javan, Ballik, and Bond, 1961]. The observed frequency variation, referred to the optical frequencies of the modes, corresponds to a stability better than one part in $10^{14}$. Since the "microphonic" perturbations shift the frequencies of both modes roughly by the same amount this kind of stability was not observed in the beat-note between modes of two different masers. In a carefully controlled environment, short-time frequency variations of the order of $20 \mathrm{c} / \mathrm{s}$ were observed [Jaseja, Javan, and Townes, 1963] corresponding to a stability of 8 parts in $10^{14}$. This stability is still far from the ultimate limit on the line-width set by spontaneous emission [Townes, 1963]. The observed stability approaches in order of magnitude the value that was to be expected in these experiments due to the thermal vibrations of the supporting rods.

The measurements on noise in optical maser amplifiers are of a more preliminary character. Measurements ${ }^{1}$ on a traveling wave $\mathrm{He}-\mathrm{Ne}$ maser

1 Private communications, E. I. Gordon, A. D. White, Bell Telephone Laboratories, Murray Hill, N.J. at a wavelength $3.39 \mu$ indicate that the noise is not much greater than the theoretical minimum $6120^{\circ} \mathrm{K}$ (expressed in terms of an effective input noise temperature).

\section{References}

Glauber, R. J., to be published in Phys. Rev.

Glauber, R. J.'(1963), Photon Correlations, Phys. Rev. Letters 10, pp. $84-86$.

Gordon, J. P. (1962), Quantum effects in communication systems, Proc. IRE 50, pp. 1898-1908.

Haus, H. A., and J. A. Mullen (1963), Equivalent circuits for quantum noise in linear amplifiers, Third International Symposium on Quantum Electronics, Paris.

Haus, H. A., and C. H. Townes (June 1962), Comments on noise in photoelectric mixing, Proc. IRE (correspondence) 50, pp. $1544-1545$.

Heffner, H. (1962), Fundamental noise limit of linear amplifiers, Proc. IRE 50, pp. 1604-1608.

Jaseja, T. S., A. Javan, and C. H. Townes (Mar. 1, 1963), Frequency stability of He-Ne masers and measurements of length, Phys. Rev. Letters 10, pp. 165-167.

Javan, A., E. A. Ballik, and W. L. Bond (Jan. 1961), Frequency characteristics of a continuous-wave He-Ne optical maser, J. Opt. Soc. Am. 52, No. 1.

Louisell, W. H. (1963), Quantum statistics of noise in linear amplifiers and attenuators, Third International Symposium on Quantum Electronics, Paris.

Louisell, W. H., A. Yariv, and A. E. Siegman (1961), Quantum fluctuations and noise in parametric processes I., Phys. Rev. 124, pp. 1646-1655.

Louisell, W. H., J. P. Gordon, and L. R. Walker (1963), Quantum fluctuations and noise in parametric processes II., Phys. Rev. 129, pp. 481-485.

Oliver, B. M. (Dec. 1961), Signal to-noise-ratio in photoelectric mixing, Proc. IRE (correspondence) 49, pp. 19601961.

Senitzky, I. R. (1960), Induced and spontaneous emission in coherent field, III, Phys. Rev. 119, p. 1807.

Senitzky, I. R. (1961), Induced and spontaneous emission in coherent field, IV., Phys. Rev. 123, pp. 1525-1537.

Senitzky, I. R. (1962), Induced and spontaneous emission in coherent field, V., Theory of molecular beam amplification, Phys. Rev. 12\%, p. 1638.

Serber, R., and C. H. Townes (1960), Limits on electromagnetic amplification due to complementarity quantum electronics, C. H. Townes ed., Columbia Univ., 233-255.

Sudarshan, E. C. G. (Apr. 1963), Equivalence of semiclassical and quantum mechanical descriptions of statistical light beams, Phys. Rev. Letters 10, pp. 277-279.

Townes, C. H. (1961), Some applications of optical and infrared masers, adv. in Quantum electronics, J. R. Singer ed. (Columbia University Press).

Wolf, E. (Apr. 1963), Basic concepts of optical coherence theory, Symposium on optical masers, Polytechnic Institute of Brooklyn. 


\title{
8. Nonlinear Optical Properties of Solids
}

\author{
P. S. Pershan*
}

A general discussion of nonlinear optical properties of solids should distinguish between what might be called coherent and incoherent nonlinear processes. The absorption of radiation and subsequent electron emission from a photosensitive surface, for example, depends on the square of the field amplitude and thus could be called a nonlinear effect of the incoherent type. A second effect of this same type but which more clearly deserves the nonlinear designation is the absorption of a photon (i.e., a pump photon) at one frequency and the subsequent emission of a lower energy photon in laser emission. These are called incoherent since the nonlinear optical phenomena is accompanied by a real transition or change of the material system.

The coherent type of nonlinear phenomena is best illustrated by the pioneering work of Franken and coworkers [Franken, Hill, Peters, and Weinreich, 1961]. A large electric field was obtained at an optical frequency by focusing the parallel beam of light emitted from a ruby laser down to a small spot within a piece of quartz. It is well known that materials respond to electric fields by becoming polarized and, if the material lacks a center of inversion symmetry, part of this polarization will be proportional to the square of the electric field. This is just the reason why crystal rectifiers, mixers, and harmonic generators work at lower frequencies and for the very same reason Franken was able to observe the blue light generated as the second harmonic of the red laser light. In this experiment, as in all the coherent nonlinear effects, the material plays a passive role. For every blue photon generated there are exactly two red photons annihilated and electromagnetic energy is exactly conserved. The nonlinear element, the quartz, is unchanged in the process and there is a very definite phase relationship between the incident red beam and the emitted blue beam. One describes this process as a coherent nonlinear phenomena.

These examples are extreme cases and can be assigned the coherent or incoherent designation without any ambiguity. In fact, however, there are phenomena that fall in between and cannot clearly be assigned to either of these two groups. Consider the case of second harmonic generation in a material that has a natural absorption near the second harmonic frequency. If the material should make an upward transition, the question arises as to whether it should be considered as if a second harmonic photon has been created and then absorbed (a coherent nonlinear process followed by linear

\footnotetext{
*Division of Engineering and Applied Physies, Harvard University, Cam. bridge, Mass.
}

absorption) or if two photons at the fundamental were absorbed directly (an incoherent nonlinear process) as in the experiments of Kaiser and Garrett [1962]. In fact, it can be either of these two depending on how near the second harmonic is to the atomic resonance frequency. For the remainder of this paper, we will restrict ourselves to phenomena that are clearly of the coherent type. The review articles of Bloembergen [1963] and Franken and Ward [1963] discuss this middle ground at greater length.

The first observation of beats between two different light sources followed soon after Franken's original experiment. Bass, Franken, et al. [1962], beat a ruby laser at room temperature and one cooled to liquid nitrogen against one another and observed the second harmonic due to each of them as well as a signal at the sum of their two frequencies.

It is immediately clear to anyone studying these effects that they can be considerably enhanced if the interacting waves all have the same speed. In the first paper on the subject, Franken mentioned that failure to satisfy this condition limited the size of the effect he could detect. Giordmaine [1962] and Maker et al. [1962], simultaneously demonstrated how one could satisfy this condition of phase matching in practice in KDP. In addition, Maker et al. [1962], demonstrated the effects of phase mismatch in quartz. Following these first experimental results, several theoretical papers appeared on the subject. Braunstein [1962] obtained expressions for the nonlinear response of semiconductors and Kleinman [1962] commented on certain phenomenological aspects of the nonlinear tensor. Kroll [1962] suggested how the nonlinearity might be used as a parametric amplifier or oscillator. The most extensive discussion of optical nonlinearities however was given by Armstrong et al. [1962]. They properly incorporate the nonlinearity into the macroscopic Maxwell's equations for dense dielectric media and gave exact solutions to the simultaneous nonlinear differential equations that describe second harmonic generation, the beating of two waves to form either a sum or difference frequency signal, and the general problem of higher harmonics. These solutions are exact in the sense that they properly describe the situation when so much power is generated at the second harmonic, for example, so that the energy of the fundamental frequency wave is significantly depleted. In addition, this paper obtains certain dispersion-symmetry relations between different elements of the nonlinear tensor. There is a fundamental relation between these symmetries and the well-known Manley-Rowe relations. 
Bloembergen and Pershan [1962] extended the previous solutions for infinite nonlinear media to include effects due to the boundaries of the material. Nonlinear generalization of the Fresnel formulas are obtained. Kleinman [1962] made further theoretical observations and in particular discussed the experimentally significant geometry of harmonic generation at the focus of a lens. Siegman [1962] suggested how the nonlinear effect could, in principle, be used to build a power limiter that would suppress the spikes observed in many of the solid state lasers.

Terhune, Maker, and Savage [1962] observed second harmonic generation in calcite by applying an external d-c electric field. Without this field, the crystal is centrosymmetric and the only second harmonic generation is due to a quadrupole effect which they observed. In this same paper, they reported the first observation of third harmonic generation.

The dispersion-symmetry relations mentioned previously [Armstrong et al., 1962] state that the constant for rectification of light should be directly related to the linear electro-optic constant in the same material. Bass, Franken, et al. [1962], observed the ratio of these constants for ordinary KDP and deuterated KDP and, consistent with theory, found them to be the same. Along the same line, Smith and Braslau [private communication] were able to beat the $3115 \AA$ line of a mercury lamp with a beam from a ruby laser $(6943 \AA)$ and observe the $5650 \AA$ beat. To the limits of their accuracy the constant for this process was not different from the constant for beating a $5460 \AA$ mercury line against the ruby to obtain a $3056 \AA$ sum frequency signal [Smith and Braslau, 1962].

Difference frequency beats at a microwave frequency might prove to be of significant value in demodulating light. M. DiDomenico et al. [1962], observed $1.3 \mathrm{Gc} / \mathrm{s}$ beats between adjacent axial modes of a ruby laser when its output is focused on a cadmium selenide crystal that is biased by a large d-c electric field.

The inverse effect of beating a microwave signal with a light in order to modulate the light wave has received much attention [Pershan and Bloembergen, 1961]. The most significant experimental work on this topic has been done by Kaminow and is well documented in his review article [Rigrod and Kaminow, 1963].

A second experiment suggested by the results of Armstrong et al. [1962], was very beautifully done by Terhune, Maker, and Savage [1963]. Using a focused beam from a ruby laser they were able to convert 20 percent of the incident red light into second harmonic blue light and observe the saturation of the effect as further increase in red intensity gave no further increase in blue light.
Further data on harmonic generation in other crystals [Savage and Miller, 1962] and from a different laser, $\mathrm{CaWO}_{4}, \mathrm{~N}_{d}^{+3}$ [Miller and Savage, 1962], has been obtained by Miller and Savage.

Most recently Pershan [1963] has given general phenomenological arguments in order to generalize the dispersion-symmetry relations, previously given [Armstrong et al., 1962] for electric dipole nonlinearities to include magnetic and quadrupole nonlinearities as well. Price [1962] has been able to obtain certain integral equations relating real and imaginary parts of the nonlinear tensors that are analagous to the well-known Kramer's-Kronig applicable to linear systems.

In addition to the above mentioned works, there were several other interesting papers on nonlinear optical effects presented at the Third International Conference on Quantum Electronics that are not explicitly reviewed here [Pershan, 1963].

\section{References}

Armstrong, J. A., Bloembergen, N., Ducuing, J. and Pershan, P. S. (1962), Phys. Rev. 12\%, 1918.

Bass, M., Franken, P. A., Hill, A. E., Peters, C. W., and Weinreich, G. (1962), Phys. Rev. Letters 8, 18.

Bass, M., Franken, P. A., Ward, J. F., and Weinreich, G. (1962), Phys. Rev. Letters 9, 446.

Bloembergen, N. (1963); Proceedings of the Institute of Electrical and Electronics Engineers, 51, 124.

Bloembergen, N., and Pershan, P. S. (1962), Phys. Rev. 128, 606.

Braunstein, R. (1962), Phys. Rev. 125, 475.

Di Domenico, M., Pantell, R. H., Svelto, O., and Weaver, J. N. (1962), App. Phys. Letters 1, 77.

Franken, P., Hill, A. E., Peters, C. W., and Weinreich, G. (1961), Phys. Rev. Letters \%, 118.

Franken, P., Ward, J. F. (1963), Rev. Mod. Phys. 35, 23.

Giordmaine, J. A. (1962), Phys. Rev. Letters 8, 19.

Kaiser, W., Garrett, C. G. B.(1962), Phys. Rev. Letters y, 229.

Kleinman, D. A. (1962), Phys. Rev. 126, 1977.

Kleinman, D. A. (1962), Phys. Rev. 128, 1761.

Kroll, N. M. (1962), Phys. Rev. 127, 1207.

Maker, P. D., Terhune, R. W., Nisenoff, M., and Savage, C. M. (1962), Phys. Rev. Letters 8, 21.

Miller, R. C., Savage, A. (1962), Phys. Rev. 128, 2175.

Pershan, P. S., and Bloembergen, N. (1961), Advances in quantum electronics, p. 187 (Columbia University Press, New York).

Pershan, P. S. (1963), Phys. Rev. 130.

Pershan, P. S. (Feb. 1963), Nonlinear optical properties of solids, Proceedings of the Third International Conference on Quantum Electronics, Paris, France (to be published). There are also several other interesting papers in this volume that are not explicitly reviewed here.

Price, P. J. (to be published), Remarks on the theory of non-linear dielectrics, Proceedings of the Lasers and Applications Symposium, Ohio State University, Columbus, Ohio, November, 1962.

Rigrod, W. W., Kaminow, I. P. (1963), Proceedings of the IEEE 51, 137.

Savage, A., and Miller, R. C. (1962), Appl. Opt. 1, 661.

Siegman, A. E. (1962), Appl. Opt. 1, 739.

Smith, A. W., Braslau, N. (1962), IBM J. Res. and Develop. 6, 361 .

Smith, A. W., and Braslau, N. (private communication).

Terhune, R. W., Maker, P. D., and Savage, C. M. (1962), Phys. Rev. Letters 8, 404.

Terhune, R. W., Maker, P. D., and Savage, C. M. (1963), Appl. Phys. Letters 2, 54 . 


\title{
9. Highlights of Progress on Satellite Devices
}

\author{
C. C. Cutler* and J. R. Pierce*
}

All of the significant "real time" satellite communication experiments so far performed have been carried out during slightly more than the past three years. The first were Project SCORE [Brown, 1960], and [Brown and Senn, 1960] and COURIER [Siglein and Senn, 1962] which were designed for delayed repetition. Next came Echo [Echo, 1961], which used a 100-ft aluminized mylar balloon as a passive reflector for transcontinental communication of speech bandwidth signals. Echo was launched on August 12, 1960 and still returns a usable signal. Plans and preparations for a larger and stiffer balloon satellite are in the making [Reiger, 1963]. There have been sporadic newspaper references to nonoriented passive satellite having gain, but such possibilities seem rather remote [Cutler, 1962].

The second experiment used the active Telstar satellite [Telstar, 1963], which successfully transmitted television across the ocean over a period of four months before radiation effects caused a serious malfunction. The Relay active satellite [Wilmotte, 1962] soon followed and has functioned intermittently in a similar capacity. A fourth communication satellite, Syncom [Meisels, 1962], intended to operate in an approximately synchronous orbit suffered an abortive launch but is expected to be in orbit soon.

An attempt was made to orbit a different sort of passive satellite, Project Westford [Morrow, 1961 and 1962], which will use a multitude of small half wave wire dipoles in a low orbit. This kind of circuit involves multiple scattering; and if broad band signals are to be transmitted, rather special modulation techniques must be used [Berg et al., 1961]. There seems to be some possibility that the presence of such an orbiting belt would interfere with other activities [Liller, 1961], but this allegation has been vocally refuted [Purcell, 1962].

Perhaps the most promising area of progress in communication satellites is in the development of attitude control systems. This problem has been discussed [Kendall et al., 1960; Roberson, 1962; and Haeussermann, 1962]. The problem of damping the oscillations in such a system may be solved by using fluids [Lewis, 1962], resonant mechanical structures [Zajac, 1962] or gyro's [Burt, 1962]. There are fundamental characteristics limiting the rate of damping, which may not be exceeded by any method [Zajac, 1963].

There are interesting possibilities in building active satellites which, although unoriented, have a useful directional radiation characteristic. Most of these are based upon the concept of the Van Atta array [Van Atta, 1959]; Hansen [1961] showed that the linear Van Atta array could profitably be used with amplification in a satellite. Davies [1963] showed that the idea could be extended to cover circular arrays.

*Bell Telephone Laboratories, Murray Hill, N.J.
A wide variety of power sources for communication satellites has been discussed from time to time, but only two seem to be serious contenders at this time. [Picquendar, 1961]. Nuclear power sources hold considerable promise, but most systems are being designed around solar cell arrays. The $\mathrm{P}$ on $\mathrm{N}$ silicon solar cell has been widely used, but it has recently been found to be less resistant to radiation damage from high energy protons [Madelkorn et al., 1960] than are $\mathrm{N}$ on $\mathrm{P}$ cells. Experience with $\mathrm{N}$ on $\mathrm{P}$ cells verified the predicted performance and gave about eight times the useful life expectancy of $\mathrm{P}$ on N cells [Brown et al., 1963].

For many applications, it is necessary to supplement solar cells with a chemical storage battery. The Nickel-Cadmium battery is most widely used. The kinetic characteristics of the Nickel-Cadmium cell are becoming better known [Thomas, 1962] and has resulted in batteries having improved properties and much greater reliability [Bomberger, Moose, et al., 1963]. The combination of $\mathrm{P}$ on $\mathrm{N}$ solar cells and a Nickel-Cadmium storage battery was first used in the United States on the Telstar satellite [Bomberger, Feldman, et al., 1963].

At present, the only satellite function which cannot readily be performed with solid state devices is the RF amplification to reasonable power levels (several watts). The traveling wave tube is most suitable for this purpose because it can be made both efficient and long lived. Several tubes are under development. It seems possible to design tubes for 10 to 20 years life expectancy [Bodmer et al., 1963]. By using periodic magnetic focusing or electrostatic focusing, they can be made very light [Nowogrodzki, 1961; Notvest et al., 1960].

The vast bulk of satellite components are semiconductor devices and passive elements; and if a satellite is to have a good chance of surviving for many years, the reliability of these components must be extreme [Ross, 1962; Peck and Wooley, 1963].

Radiation poses a particular hazard to solid state components in satellites. One well-known type of radiation damage is a reduction of carrier lifetime because of bulk damage in the semiconducting material. A more recently discovered effect is a temporary degradation of transistor performance due to the effect of ionization of the gas in the device and resulting ionization of the surface [Peck, Blair, et al., 1963].

\section{References}

Berg, R. S., D. B. Eshleman, J. N. Harris, R. M. Horowitz, I. L. Lebow, W. H. Long, N. J. Morrison, F. Nagy, and N. L. Doggett (1961), ed., The dicon system, Lincoln Laboratory Technical Report No. 251.

Bodmer, M. G., J. P. Laico, and E. G. Olsen (July 1963), Satellite traveling wave tube, Bell System Tech. J.

Bomberger, D. C., D. Feldman, D. E. Trucksess, S. J. Brolin and P. W. Ussery (July 1963), The spacecraft power supply system, Bell System Tech. J. 
Bomberger, D. C., and L. F. Moose, et al. (1963), Nickelcadmium cells for the telstar battery, Telstar issue of Bell System Tech. J.

Brown, S. P. (July 1960), Project SCORE: Signal communication by orbiting relay equipment, IRE Trans. Military Electronies MIL-4, No. 2-3, pp. 193-194.

Brown, S. P., and G. F. Senn (Apr. 1960), Project SCORE: pp. 624-630. Proc. IRE 48.

Brown, W. L., J. Gabbe (July 1963), Results of the Telstar radiation experiment, Bell System Tech J.

Burt, E. G. C. (1962), The influence of cyclic torques on the attitude control of earth-pointing satellites, Space Radio Communication, ed. by G. M. Brown (Elsevier Publishing Company, Amsterdam-New York-London).

Cutler, C. C. (Sept. 1962), Problem in nonoriented directional passive satellite repeaters, ARS Journal, pp. 1400-1401.

Davies, D. E. N. (Mar. 1963), Some properties of Van Atta arrays and the use of two-wave amplification in the delay paths, Proc. IEE 110, No. 3, 507-512, (London).

Haeussermann, W. (Feb. 1962), Recent advances in attitude control of space vehicles, ARS Journal, 32, 188-195.

Hansen, R. C. (June 1961), Communication satellites using arrays, Proc. IRE 49, 1066-1074.

Kendall, P. E., and R. E. Stalcup (Apr. 1960), Attitude reference devices for space vehicles, Proc, IRE 48, 765-770.

Lewis, J. A. (1962), Proceedings of the Fourth U.S. National Conference on Applied Physics, American Society of Mechanical Engineers, pp. 251-254. Liller, W. (Apr. 1961), Report on the effects of project Westford on optical astronomy, Astron. J. 66, No. 3, 114-116.

Madelkorn, J., et al., A new radiation-resistant high-efficiency solar cell, delivered at a meeting on Radiation Damage to Semiconductors by High-Energy Protons, sponsored by ANSA, Washington, D.C. (Oct. 20, 1960). Available from U.S. Army Signal Res. and Dev. Lab., Fort Monmouth, New Jersey.

Meisels, M. (Jan. 8, 1962), Communication satellite: Challenge and progress in four microwave systems, Electronic Design 10, No. 2, 156-171, Jan. 8, 1962.

Morrow, W. E. (Apr. 1961), Properties of orbiting dipole belts, Astron. J. 66, No. 3, 107-113.

Morrow, W. E. (1962), Communication by orbiting dipoles, Space Radio Communication, ed. by G. M. Brown (Elsevier, Amsterdam-New York-London).

Notvest, R. A., and A. W. Scott (1960), A feather weight traveling-wave amplifier for communication satellite, pp. 436-439, Proc. National Aeronautical Electronics Conference, Annual Report, Dayton, Ohio.
Nowogrodzki, M., Traveling Wave Tubes for Satellite Microwave Repeater Applications, Electron Tube Division, Harrison, N.J., 13th Annual National Aerospace Electronies' Conference, May 8-10, 1961.

Peck, D. S., R. R. Blair, W. L. Brown, and F. M. Smits (Jan. 1963), Surface effect of radiation on transistors, Bell System Tech. J., vol. 42, No. 1.

Peck, D. S., and M. C. Wooley (July 1963), Component design, construction and evaluation for satellites, Bell System Tech. J.

Picquendar, J. E. (1962), Differents Systems de Production D'Energie a bord des Satellites, Space Radio Communications, ed. by G. M. Brown, pp. 224-239 (Elsevier, Amsterdam-New York-London).

Purcell, E. M. (Feb. 1, 1962), The "Needles" experiment, The New Scientist, 13, No. 272, p. 245.

Reiger, S. H. (Feb. 1963), A study of passive communication satellites, R-415-NASA (The Rand Corporation, Santa Monica, Calif.).

Roberson, R. E. (1962), Stabilization and station-keeping of communication satellites, Space Radio Communications, ed. by G. M. Brown (Elsevier Publishing Company, Amsterdam-New York-London).

Ross, I. M. (1962), Reliability of components for communication satellites, Space Communications, ed. by G. M. Brown (Elsevier Publishing Company, AmsterdamNew York-London).

Siglin, P. W., and G. Senn (1962), The Courier satellite, Communications Satellites, pp. 187-197, ed. by L. J. Carter (Academic Press, London and New York).

Thomas, U. B. (1962), Kinetic basis for the operating characteristics of nickel-cadmium batteries, Proceedings of the Third International Symposium on Batteries, Bumemouth, England.

Van Atta, L. C. (Oct. 6, 1959), Electromagnetic reflector, U.S. Patent No. 2,908,002.

Wilmotte, R. M. (Aug. 1962), NASA's relay spacecraft, Aerospace Eng.

Zajac, E. E. (Feb. 1963), Limits on the damping of two-body gravitationally oriented satellites, AIAA Journal 1, No. 2 , $498-500$.

Zajac, E. E. (Dec. 1962), Damping of a gravitationally oriented two-body satellite, ARS Journal 32, 1871-1875.

The Telstar satellite, entire issue of Bell System Tech. J. in three volumes, July 1963.

Project Echo, entire issue of Bell System Tech. J. XL, No. 4, July 1961.

\section{Waves in Plasmas*}

\section{A. Bers ${ }^{1}$ and P. Chorney ${ }^{2}$}

The continuing and increasing interest in plasmas has brought about a thorough exploration of the characteristic wave properties of a plasma. For the years $1960-1962$, to be reviewed here, the U.S. literature on this subject has been so enormous that we shall have to restrict this review to only a few of the many interesting aspects of this field. In the following, we, therefore, shall not review work on: nonlinear properties of plasmas, radiation from plasmas, and work exclusively related to MHD and collisiondominated plasmas.

*This work was supported in part by the U.S. Army, the Air Force Office of Scientific Research, and the Office of Naval Research; and in part by the National Science Foundation (Grant G-24073).

${ }^{1}$ Research Laboratory of Electronics, M.I.T., Cambridge, Mass.

2 Microwave Associates, Burlington, Mass.
A brief survey is given of experimental studies on interactions between plasmas, electromagnetic waves, and electron beams. It is noted that experimental activity in this area of plasma physics is on the increase, and satisfactory correlation between theory and experiment has been obtained in many cases.

\section{Books and General Reviews}

A large amount of the research in plasmas has been made available in various text books, research monographs, conference proceedings, and review articles.

The text books [Glasstone and Loveberg, 1960; Rose and Clark, 1961] cover a wide range of topics on the properties of plasmas, with most of the discussed applications related to the field of fusion. Detailed description of waves in plasmas has ap- 
peared in two books that are more in the nature of advanced texts or research monographs. One of these [Allis, Buchsbaum, and Bers, 1962] deals with both free and guided waves in plasmas. The other [Stix, 1962] gives an excellent description of free waves in a hot plasma. Mathematical tables [Fried and Conte, 1961] that aid in the analysis of the hot plasma dispersion equation were also published. The second edition of Spitzer's Monograph [Spitzer, 1962] also contains an expanded treatment of waves in plasmas.

The proceedings of several conferences have been edited in book form. Among these are: The Second Geneva Conference on The Peaceful Uses of Atomic Energy [Allis, 1960]; The International Symposium on Plasma Dynamics at Woods Hole 1958 [Clauser, 1960]; The Stanford Research Institute 1957-1958; Plasma Physies Seminars [Drummond, 1961]; and the Lockheed Fifth Annual MHD Symposium [Mitchner, 1961]. The proceedings of some conferences have also appeared in special issues and as supplements of journals: Proceedings of the 1959 International Plasma Physies Institute [Drummond, 1961]; proceedings of the 1960 International Symposium on Magneto-Fluid Dynamics (1960); and the 1961 Salzburg Conference on Plasma Physics (1962).

Several review articles have been devoted to the linearized description of a plasma and its wave propagation properties [Bernstein and Trehan, 1960; Pai, 1960, and Oster, 1960 and 1961].

\section{References}

Allis, W. P. (1960), ed., Nucl. Fusion (D. Van Nostrand Co. Inc.). 1960

Allis, W. P., S. J. Buchsbaum, and A. Bers (1962), Waves in anisotropic plasmas (The M.I.T. Press).

Bernstein, I. B., and S. K. Trehan (1960), Plasma oscillations (1), Nucl. Fusion 1, 1, 3-41.

Clauser, F. H. (1960), Plasma dynamies (Addison-Wesley Publishing Co. Inc.).

Drummond, J. E. (1961), Plasma physics (McGraw-Hill Book Co., New York, N.Y.).

Drummond, J. E. (1961), ed., Proceedings of the 1959 International Plasma Physies Institute, Journal of Nuclear Energy Part C $\boldsymbol{2}, 1-4$.

Fried, B. D. (1961), The plasma dispersion function (Academic Press). 1961.

Glasstone, S. and R. H. Lovberg (1960), Controlled thermonuclear reactions (an introduction to theory and experiment) (D. Van Nostrand).

International Symposium on Magneto-Fluid Dynamics, Williamsburg, Virginia, and Washington, D.C., Rev. Mod. phys. 32, 4, 1960 (special issue proceedings).

Mitchner, M. (1961), ed., Radiation and wave plasma (Stanford U. Press).

Oster, L. (1961), Emission, absorption and conductivity of a fully ionized gas at radio frequencies, Rev. Mod. Phys. 33, $4,525-543$.

Oster, L (1960), Linearized theory of plasma oscillations, Rev. Mod. Phys. 32, 1, 141-68.

Pai, S. I. (1960), The wave motions of small amplitude in a fully ionized plasma without external magnetic field, Rev. Mod. Phys., 3\%, 4, 882-7.

Rose, D. J., and M. L. Clark (1961), Plasmas and controlled fusion (The M.I.T. Press).

Salzburg 1961 Conference, Plasma physics and controlled nuclear fusion research, Journal of Plasma Physics and Thermonuclear Fusion (1962). (Supplement Part 1 and 2 International Atomic Energy Agency, Vienna, Austria.
Spitzer, H (1962), Physies of fully ionized gases, 2d ed. (Interscience Publishing Inc., New York).

Stix, T. H. (1962), The theory of plasma waves, (MeGrawHill Book Co., New York, N.Y.).

\section{Macroscopic Description of a Plasma}

Much emphasis has been placed upon determining the proper conductivity tensor for a plasma starting from kinetic theory. The $d-c$ conductivity for a partially ionized gas in the absence of an applied magnetic field has been treated [Dreicer, 1960]; this includes inelastic collisions and the two-body Coulomb interactions. The high-frequency conductivity in a magnetic field [Kelly, 1960] has been treated with a full evaluation of the binary collision integral in the Focker-Planck approximation. A different approach to the solution of the linearized Boltzman equation is to consider the conductivity as the kernel of an integral equation [Drummond et al., 1961]; this approach is readily applicable to an inhomogeneous plasma. For a collisionless plasma the conductivity and damping (Landau) has again received some attention [Buneman 1961]. More recently attention has been directed toward evaluating the effects of collective dynamics [Dawson and Oberman, 1962; Oberman, Ron, and Dawson 1962].

\section{References}

Buneman, O. (June 1961), Gas law and conductivity of a collision-free plasma, Phys. Fluids 4, 669-680.

Dawson J., and C. Oberman (May 1962), High frequency conductivity and the emission and absorption coefficients of a fully ionized plasma, Phys. Fluids 5, 517-524.

Drummond, J. E., R. A. Gervious, and B. G. Springer (Jan, 1961), The concept of conductivity, J. Nucl. Energy Part C $\boldsymbol{2}, 1-4,98$.

Dreicer, H. (Jan. 1960), Electron velocity distributions in a partially ionized gas, Phys. Rev. 11\%, 2, 343.

Kelly, D. C. (July 1, 1961), Microwave conductivity of a plasma in a magnetic field, Phys. Rev. 119, No. 1, 27-39. Oberman, C., A. Ron, and J. Dawson (Dec. 1962), High frequency conductivity of a fully ionized plasma, Phys. Fluids 5, 12, 1514.

\section{Free Waves}

The theory of waves in an unbounded plasma is given in great detail in the books mentioned in section 1 [Allis, Buchsbaum, and Bers, 1962] and [Stix, 1962].

The Landau damping theory has again received a great deal of attention. The details of this have been given for a hot electron-ion plasma [Fried and Gould, 1961]. A very clear picture of the damping has been obtained from energy exchange considerations of multiple beams [Dawson, 1960 and 1961]. Also, the effect of (close range) collisions on Landau damping has been investigated [Platzman and Buchsbaum, 1961]. Attention has also been directed to cyclotron damping (the analog of Landau damping at cyclotron frequencies) in a collisionless plasma [Stix, 1960] and [Scarf, 1962].

Considerable attention has been given to the description of free waves from the BoltzmanVlasov equations, and the mathematics of their 
solution [Lewis and Keller, 1962; Backus 1960]; see also Bernstein and Trehau, section 1.

The relativistically hot plasma has also been solved including the effects on damping [Buti, 1962] and [Imre, 1962].

The description of free waves from transport equations is by now fairly complete for isotropic pressures and no heat flow [Tanenbaum, 1961; Pai, 1962]. Extensions to the case of an anisotropic pressure have been started [Jagoi, 1962].

For the cold plasma, the oscillations with multiple ion species has been treated [Buchsbaum, 1960].

\section{References}

Backus, G. (May-June 1960), Linearized plasma oscillations in arbitrary electron velocity distributions, J. Math. Phys., 1, No. 3, 178-91.

Backus, G. E. (Nov.-Dec. 1960), Linearized plasma oscillations in arbitrary electron distributions, J. Math. Phys. 1, No. 6, 559 .

Buchsbaum, S. J. (May-June 1960), Resonance in a plasma with two ion spheres, Phys. Fluids, 3, 418-419.

Buti, B. (Jan. 1960), Plasma oscillations and Landau Damping in a relativistic gas, Phys. Fluids 5, $1-5$.

Dawson, J. (Apr. 15, 1960), Plasma oscillations of a large number of electron beams, Phys. Rev. 118, No. 2, 381-9.

Dawson, J. (July 1961), On Landau damping, Phys. Fluids, 4, $869-874$.

Fried and Gould (Jan. 1961), Longitudinal ion oscillations in a hot plasma, Phys of Fluids 4, No. 1.

Imre, K. (Apr. 1962), Oscillations in a relativistic plasma, Phys. Fluids 5, 459-466.

Jaggi, R. K. (Aug. 1962), Wave motion in a plasma with anistropic pressure, Phys. Fluids, 5, 949-962.

Lewis, R. M., and J. B. Keller (Oct. 1962), Conductivity tensor and dispersion equation for a plasma, Phys. Fluids 5, $1248-1263$.

Pai, S. J. (Feb. 1962), Wave motions of small amplitude in a fully ionized plasma under applied magnetic field, Phys. Fluids 5, 234-240.

Platzman, P. M., and S. J. Buchsbaum, (Oct. 1961), Effect of collisions on the Landau damping of plasma oscillations, Phys. Fluids, 4, 1288-1292.

Scarf, F. L. (Jan. 1962), Landau damping and the attenuation of whistlers, Phys. Fluids 5, 6-13.

Stix, T. H. (Jan. 1960), Absorption of plasma waves, Phys. Fluids, 3, 19-32

Tanebaum, B. S. (Oct. 1961), Dispersion relations in a stationary plasma, Phys. Fluids 4, 1262-1272.

\section{Plasma Waveguides}

The theory of guided waves in cold plasmas of finite extent is treated in the book mentioned in section 1 [Allis, Buchsbaum, and Bers, 1962]. Many new dispersion characteristics have been found. Detailed computations on the fast waves in an electron plasma waveguide have been made [Bevc and Everhart, 1962]. It also has been shown that backward waves and complex waves exist on an isotropic, plasma slab [Oliner and Tamir, 1962]. Computations on the complex waves in a plasma filled waveguide with a longitudinal magnetic field have also been given [Chorney, 1962].

Perturbation theory as applied to cold, anisotropic plasma waveguides and resonators has been carried out with detailed examples [Buchsbaum, Mower, and Brown, 1960] and [Mower and Buchsbaum, 1962].

Very few boundary value problems have been solved for the warm plasma. We mention a few of the problems that have been attempted: Acoustic wave excitation for a semi-infinite plasma [Turcotte and Schubert, 1961]; ion cyclotron waves in a bounded geometry [Engelhardt and Dougal, 1962; and the Green's function approach [Weitzner, 1962].

\section{References}

Buchsbaum, S. J., L. Mower, and S. C. Brown (Sept.-Oct. 1960), Interaction between cold plasmas and guided electromagnetic waves, Phys. Fluids 3, 806-819.

Chorney, P. (1962), Power and energy relations in bidirectional waveguides, Proc. Symp. on Electromagnetic and Fluid Dynamics of Gaseous Plasma, Polytechnic Press.

Engelhardt, A. G., and A. A. Dougal (Jan. 1962), Dispersion of ion cyclotron waves in magnetoplasmas, Phys. Fluids 5, No. 1, 29.

Beve, V., and T. Everhart (Sept. 1962), Fast waves in plasma-filled waveguides, J. Electron. 13, 3, 185.

Mower, L., and S. J. Buchsbaum (Dec. 1962), Interaction between cold plasmas and guided electromagnetic waves II, Phys. Fluids 5, 1545-1551.

Oliner, A. A., and T. Tamir (Jan. 1962), Backward waves on isotropic plasma slabs, J. Appl. Phys. 33, No. 1, 231-33.

Turcotte, D. L., and G. Schubert (Sept. 1961), Interaction of low frequency electromagnetic waves with a plasma, Phys. Fluids 4, 1156-1161.

Weitzner, H. (Aug. 1962), Green's function for the linearized Vlasov equation, Phys. Fluids 5, 933-946.

\section{Electron Beam Waves}

Considerable attention has been devoted to the study of the small-signal conservation principles for electron beam systems. Energy and power theorems have been generalized for relativistic irrotational beams and cold plasmas [Bers and Penfield, 1962], and for nonrelativistic rotational beams [Bobroff, Haus and Kluver, 1962]. Approximate relations for energy and power in thin irrotational beams [Rigrod, 1960] have been derived. Conservation laws for interactions with beams have been put into a formal matrix form [Pease, 1960]. Studies of the conservation principles for small-signal momentum and stress have also been initiated [Sturrock, 1960], [Pierce, 1961].

Analyses of wave propagation have been given for the filamentary electron beam [Siegman, 1960], and for the crossed-field, thick, sheet-beam [Hershenov, 1960 and 1961]. Other detailed studies of beam waves were presented at the International Congress on Microwave Tubes [Munich, 1960 and Hague, 1962]. Renewed attention has also been given to the effect of velocity spread in beams and the damping of space-charge waves [Berghammer, 1962].

The instabilities occurring in high density beams as well as the interaction of beam waves with circuits have been reviewed for plasma applications [Pierce, 1961]. The potential minimum instability in diodes has been analyzed in detail and its time behavior has been computed numerically [Birdsall and Bridges, 1961]. 


\section{References}

Bers, A., and P Penfield, Jr. (Jan. 1962), Conservation principles for plasmas and relativistic electron beams, IRE Trans. PGED 9, 1, 12.

Berghammer, S. (Apr. 1962), Landau damping of space charge waves, J. Appl. Phys. 33, 4, 1499.

Birdsall, C. K., and W. B. Bridges (Dec. 1961), Space-charge instabilities in electron diodes and plasma convections J. Appl. Phys. 3\%, 12, 2611.

Bobroff, D. H., H. A. Haus, and J. W. Kluver (Oct. 1962), On the small-signal power theorem of electron beams, J. Appl. Phys. 33, 2932.

Hershenov, B., A small-signal field theory of crossed-field amplifiers applicable to thick beams, IRE Trans. PGED $\boldsymbol{y}$, 3, 163 (July 1960); IRE Trans PGED 8, 1, 12 (Jan. 1961).

Microwave Tubes: Proceedings of the International Congress on Microwave Tubes, Munich, June 7-11, 1960, J. Wosnick, ed., (Academic Press, Inc., New York, N.Y., 1961); Proceedings of the Hague Congress Sept. 1962 (in press).

Pease, M. C., (Nov. 1960), Conservation laws of an interacting electron beam, J. Appl. Phys. 31, 11, 2028.

Pierce, J. R. (Jan. 1961), Critical points in the theory of electron beam devices, J. Nucl. Energy, Part C: Plasma Physics 2, Nos. 1-4, 73-80.

Pierce, J. R. (Jan. 1961), Instabilities and growing waves in electron beam devices, J. Nucl. Energy, Part C: Plasma Physics, 2, Nos. 1-4, 135-137.

Pierce, J. R. (Dec. 1961), Momentum and energy of waves, J. Appl. Phys. 32, 12, 2580.

Rigrod, W. W. (July 1960), Power flow and stored energy in thin electron beams, J. Appl. Phys. 31, 7, 1147.

Siegman, A. E. (Jan. 1960), Waves on a filamentary electron beam in a transverse-field slow-wave circuit, J. Appl. Phys. 31, 1,17 .

Sturrock, P. A. (Nov. 1960), In what sense do slow waves carry negative energy, J. Appl. Phys. 31, 11, 2052.

\section{Stream-Plasma Instabilities}

A great deal of attention has been directed toward an understanding of the possible instabilities that may arise in plasmas.

Under the general designation of two-stream plasma systems a great variety of instabilities are found. These occur in non-Maxwellian plasmas [Penrose, 1960], in plasmas with doubly lumped distributions [Ichimaru, 1962], or in distributions with relative drift [Jackson, 1960]. Similarly, instabilities occur in contrastreaming plasmas [Kellogg and Liemohn, 1960 and Ek, Kahalas, and Tidman, 1962]. Related instabilities are the electron and ion runaway [Dreicer, 1960] and ion wave instability [Bernstein, Frieman, Kulsurd, and Rosenbluth, 1960], [Bernstein and Kulsurd, 1960], and the current carrying plasma [Bernstein and Kulsurd, 1961], [Buneman, 1962].

Instabilities can also arise because of inhomogeneities in the plasma [Frieman and Pytee, 1961] or in the magnetic field [Krall and Rosenbluth, 1961 and $1962]$.

Instabilities in plasmas with an injected electron beam are receiving increasing attention. Analyses for a one-dimensional, cold plasma system, in the absence of a magneric field have been given [Neufeld and Doyle, 1961; Neufeld, 1962]. Excitation of a plasma by a beam of finite cross section has also been studied [Sturrock, 1960], and used as an amplifying mechanism for microwaves [Boyd, Gould, and Field, 1961] and [Crawford and Kino, 1961]. Analyses of beam plasma interaction with great theoretical detail is also available [Watson et al., 1960] [Frieman et al., 1962]. Finally, a study has been made of the instabilities in an ion beam crossing a magnetic field as occurs in the Oak Ridge experiments [Burt and Harris, 1961].

\section{References}

Bernstein, I. B., and R. M. Kulsurd (Aug. 1961), Stability of a current-carrying plasma, Phys. Fluids 4, 1037-1039. Bernstein, I. B., and R. M. Kulsurd (Nov. 1960), Ion wave instabilities, Phys. Fluids 3, No. 6, 937-945.

Bernstein, I. B., E. A. Frieman, R. M. Kulsurd, and M. N. Rosenbluth (Jan. 1960), Ion wave instabilities, Phys. Fluids 3, 136-137.

Boyd, G. D., R. W. Gould, and L. M. Field (Dec. 1961), Interaction of a modulated electron beam with a plasma, Proc. IRE 49, 12, 1906.

Buneman, O., Instability of electrons drifting through ions across a magnetic field, Plasma Physics, 4, No. 2, 111-117, April 1962.

Burt, P., and E. G. Harris (Nov. 1961), Unstable cyclotron oscillations in a cylindrical plasma shell, Phys. Fluids $\mathbf{4}$, 1412-1416.

Crawford, F. W., and G. S. Kino (Dec. 1961), Oscillations and noise in low pressure de discharge, Proc. IRE 49, 12, 1767.

Dreicer, H. (Jan. 1960), Electron and ion runaway in a fully ionized gas. II., Phys. Rev. 11\%, No. 2, 329-43.

Ek, F., S. L. Kahalas, and D. A. Tidman (Mar. 1962), Instability of contrastreaming plasmas with resonance distribution functions, Phys. Fluids 5, 328-333.

Frieman, E. A., M. L. Goldberger, K. M. Watson, S. Weinberg, and M. N. Rosenbluth (Feb. 1962), Two-stream instability in finite beams, Phys. Fluids 5, 196-209.

Frieman, E., and A. Pytte (Aug. 1961), Electrostatic instabilities in slightly inhomogeneous plasmas, Phys. Fluids 4, 1026-1031.

Ichimaru, S. (Oct. 1962), Wave properties of a plasma with a doubly lumped velocity distribution, Phys. Fluids 5, 1264-1271.

Jackson, E. A. (Sept.-Oct. 1960), Drift instabilities in a Maxwellian plasma, Phys. Fluids 3, 786-792.

Kellogg, P. J., and H. Liemohn (Jan.-Feb. 1960), Instability of contrastreaming plasmas, Phys. Fluids 3, 40-44.

Krall, N. A., and M. N. Rosenbluth (Nov. 1962), Trapping instabilities in a slightly inhomogeneous plasma, Phys. Fluids 5, 1435-1446.

Krall, N. A., and M. N. Rosenbluth (Feb. 1961), Stability of a slightly inhomogeneous plasma, Phys. Fluids 4, 163-172.

Neufeld, J. (July 1962), Electromagnetic properties of a plasma-beam system, Phys. Rev. 127, 346-359.

Neufeld, J., and P. H. Doyle (Feb. 1961), Electromagnetic interaction of a beam of charged particles with plasma, Phys. Rev. 121, No. 3, 654-8.

Penrose, O. (Mar.-Apr. 1960), Electrostatic instabilities of a uniform non-Maxwellian plasma, Phys. Fluids 3.

Sturrock, P. A. (Mar. 1960), Excitation of plasma oscillations, Phys. Rev. 117, 1426-1429.

Watson, K. M., S. A. Bludman, and M. N. Rosenbluth (Sept.-Oct. 1960), Statistical mechanics of relativistic streams, Phys. Fluids 3, No. 5, 741-747, 747-757, I and II parts.

\section{Experimental Investigations}

Interactions between plasmas and electromagnetic waves have been applied extensively as diagnostic tools. Novel microwave diagnostic techniques have been used to determine high densities such that $\omega_{p}>>\omega$ [Anderson, 1961], and density profiles of transient and spatially varying plasmas have been determined by a microwave transmission technique [Wharton and Slager, 1960]. The multiple reso- 
nances associated with the Dattner-mode method of measuring plasma densities are still being investigated [Hershberger, 1960, 1961; Hershberger and Petroff, 1962]; multiple resonances have also been observed when microwaves are scattered from a plasma column with the electric field parallel to the axis [Willis and Petroff, 1962].

Experimental evidences of Landau damping have been observed. In propagation studies on ion acoustic waves in highly ionized plasmas, nondissipative damping has been seen [Wong, D'Angelo, and Motley, 1962], and rapidly damped signals have been measured on very slowly drifting electron beams [Coulton, Hershenov, and Paschke, 1962].

The wave properties of plasma columns have been utilized in experimental microwave components. These components perform as theoretically predicted. Transmission of signals through a $3000 \mathrm{Mc} / \mathrm{s}$ $\mathrm{TE}_{111}$ cavity loaded with a coaxial plasma column has been studied; a static magnetic field was applied to the column and maximum transmission was obtained at cyclotron resonance [Olthius, 1961]. A plasma column has been used in a long coupling slot between two UHF rectangular waveguides to give a variable directional coupler; the coupler was variable from a minimum of $3 \mathrm{db}$ with little attendant reflections [Willis, 1962]. The dipole resonance of a cylindrical plasma column has been used to make an electronically tunable band-pass filter in the 3000 $\mathrm{Mc} / \mathrm{s}$ band [Kaufman and Steier, 1962].

Several beam-plasma interaction experiments have been reported. The interactions are basically the two-stream instability which occur near plasma and cyclotron resonances. Substantial amplification of signals in the $3000 \mathrm{Mc} / \mathrm{s}$ band has been obtained by interacting a helix-modulated electron beam with a contact-ionization cesium plasma [Allen and Kino, 1961]. Further details have been reported on earlier interaction experiments with modulated beams [Boyd, Gould, and Field, 1961]. Many workers have studied self-excited oscillations that are sustained by beam-plasma interactions. Very strong oscillations have been investigated in beam-generated plasmas [Targ and Levine, 1961; Crepeau and Keegan, 1962]. Interactions have been observed which are intense enough to produce a microwave avalanche breakdown of the gas, break up of the beam, and $x$ rays [Getty and Smullin, 1962]. Oscillation frequencies could be identified with plasma and cyclotron frequencies. Experiments involving oppositely directed electron beams interacting with an independently generated plasma have resulted in oscillations near plasma frequency and verification of the Bohm and Gross two-beam theory [Kofoid, $1960,1962]$. The two-stream instability has been identified in a low pressure discharge as being responsible for coherent oscillations; the frequency of oscillation has been ascertained as the plasma frequency [Putnam, Collins, and Oleson, 1961].

\section{References}

Allen, M. A., and G. S. Kino (1961), Interaction of an electron beam with a fully ionized plasma, Phys. Rev. Letters 6, 163, 1961.

Anderson, J. M. (1961), Cavity method for measurement of high electron densities in plasmas, Rev. Sci. Instr. 32, 975.

Boyd, G. D., R. W. Gould, and L. M. Field, (1961), Interaction of a modulated electron beam with a plasma, Proc. IRE 49, 1906.

Caulton, M., Hershenov, and F. Paschke (1962), Experimental evidence of Landau damping in electron beams, J. Appl. Phys. 33, 800.

Crepeau, P. J., and T. Keegan (1962), A beam plasma surface wave interaction, IRE Trans. Microwave Theory Tech. MTT-10, 391.

Getty, W. D., and L. D. Smullin (1962), Generation of a hot, dense plasma by a collective beam-plasma interaction, Phys. Rev. Letters 9, 3.

Hershberger, W. D. (1960), Absorption and reflection spectrum of a plasma, J. Appl. Phys. 31, 417.

Hershberger, W. D. (1961), Radiation field and $Q$ of a resonant cylindrical plasma column, Phys. Fluids 4, 740.

Hershberger, W. D., and I. Petroff (1962), Magnetic effects in a plasma column irradiated with microwaves, J. Appl. Phys. 33, No. 1, 227.

Kaufman, I., and W. H. Steier (1962), A plasma-column band-pass microwave filter, IRE Trans. Microwave Theory Tech. MTT-10, 431 .

Kofoid, M. J. (1960), Experimental excitation of electron oscillations in a plasma without sheaths, Phys. Rev. Letters 4, 556 .

Kofoid, M. J. (1962), Experimental two-beam excitation of plasma oscillations, Phys. Fluids 5, 712.

Olthuis, R. W. (1961), A gas-discharge microwave power coupler, Proc. IRE 49, 949.

Putnam, L. H., H. D. Collins, and N. L. Oleson (1961), Experimental evidence for beam-plasma interaction in a lowpressure argon discharge, Phys. Rev. Letters $\boldsymbol{y ,} 77$.

Targ, R., and L. P. Levine (1961), Backward-wave microwave oscillations in a system composed of an electron beam and a hydrogen gas plasma, J. Appl. Phys. 32, 731.

Wharton, C. B., and D. M. Slager (1960), Microwave determination of plasma density profiles, J. Appl. Phys. 31, 420.

Willis, J. (1962), A plasma controlled directional coupler, IRE Trans. Microwave Theory Tech. MTT-10, 383.

Willis, J., and I. Petroff, (1962), Resonances in a cylindrical plasma column, IRE Trans. Microwave Theory Tech. MTT-10, 395.

Wong, A. Y., N. D'Angelo, and R. W. Motley (1962), Propagation and damping of ion acoustic waves in highly ionized plasmas, Phys. Rev. Letters 9.

(Paper 68D5-365) 